\title{
Plants and Surgery: The Protective Effects of Thymoquinone on Hepatic Injury-A Systematic Review of In Vivo Studies
}

\author{
Aysun Tekbas ${ }^{1, *}$, Jutta Huebner ${ }^{2}$, Utz Settmacher ${ }^{1}$ and Uta Dahmen ${ }^{1}$ \\ 1 Department of General, Visceral and Vascular Surgery, University of Jena, 07743 Jena, Germany; \\ Utz.Settmacher@med.uni-jena.de (U.S.); Uta.Dahmen@med.uni-jena.de (U.D.) \\ 2 Clinic for Internal Medicine II, Department of Hematology and Internal Oncology, University of Jena, \\ 07743 Jena, Germany; Jutta.Huebner@med.uni-jena.de \\ * Correspondence: Aysun.Tekbas@med.uni-jena.de; Tel.: +49-3641-9322674
}

Received: 28 February 2018; Accepted: 28 March 2018; Published: 5 April 2018

Abstract: Multimodal treatment concepts including liver transplantation for hepatocellular carcinoma (HCC), extended resection methods and neoadjuvant chemotherapy for colorectal liver metastasis significantly improve patients' outcome. However, surgery-induced hepatic ischemia-reperfusion injury (IRI) and chemotherapy-associated hepatotoxicity result in hepatocellular damage and compromised liver function. Activation of common key pathways in ischemic liver and hepatotoxic injury results in oxidative stress, inflammatory responses and apoptosis causing organ damage. Controlling liver damage before and during surgery is essential for the postoperative outcome. Nigella sativa has a long tradition as a natural remedy. In the essential oil, Thymoquinone (TQ) was identified as the main component and responsible for most of the therapeutic effects. Therefore, this systematic review aimed to summarize the hepatoprotective effects of TQ and its potential suitability to improve surgical outcome by reducing surgical ischemic injury and hepatotoxicity of neoadjuvant chemotherapy. The key findings can be summarized as TQ having strong antioxidant, anti-inflammatory, antifibrotic, anti-/proapoptotic and anticarcinogenic effects. Almost no side effects were reported irrespective of a large dose range, suggesting a wide therapeutic window. These results give rise to the expectation that TQ could evolve to a novel powerful drug to reduce hepatic injury.

Keywords: Nigella sativa; Thymoquinone; natural remedy; liver; ischemia/reperfusion injury; hepatotoxicity; chemotherapy; hepatic injury

\section{Introduction}

\subsection{Current Treatment Concepts and Hepatotoxicity}

Surgical resection is the gold standard for curative treatment of colorectal liver metastasis [1] and hepatocellular carcinoma (HCC) [2]. However, only 10-20\% of patients with liver metastasis and $<30 \%$ with HCC are eligible for surgery due to the tumor size, location and/or the degree of liver function [3,4]. Those patients remarkably benefit from multimodal treatment concepts consisting of neoadjuvant chemotherapy for colorectal liver metastasis [5] as well as from extended resection methods [6] and liver transplantation for HCC [7,8].

Neoadjuvant chemotherapy is applied to downsize the tumor burden in the liver. Reduction of tumor mass may turn a primarily unresectable tumor into a resectable one, enabling a potentially curative resection for an increasing number of patients. Curative resection is the prerequisite for prolonging recurrence-free survival time [9]. 
Per contra, modern chemotherapy regimens such as Oxaliplatin and Irinotecan are associated with severe damage of the liver parenchyma, mainly leading to sinusoidal obstruction syndrome (SOS) and steatohepatitis [10]. Respectively, both injuries may increase the risk for post-hepatectomy morbidity [11].

The injury in SOS is caused by the damage to endothelial cells in the liver leading to their necrosis and extrusion into sinusoids which results in obstruction and congestion. Furthermore, stellate cells are activated and produce extracellular matrix and collagens. Due to loss of endothelial function, congestion and possibly direct toxicity of the implicated agents, hepatocellular necrosis is caused $[10,12,13]$.

Steatohepatitis is due to an imbalance between triglyceride accumulation and elimination in the liver together with the activation of inflammatory cytokines. This results in interlobular inflammation and ballooning degeneration of hepatocytes [10,14].

\section{Transplantation and IRI}

In cases of HCC, liver resection can only be offered to patients with little impairment of hepatic function or to those needing only a minor resection. Liver transplantation is a curative option treating the tumor and the underlying liver disease [8]. Modern transplantation medicine includes well-developed surgical techniques, preservation strategies and immunosuppressive drugs making cadaveric or living-donor transplantations possible. Nevertheless, the inevitable hepatic IRI still remains a major problem in liver transplantation, potentially leading to hepatocellular dysfunction, aggravating liver rejection and ultimately contributing to the development of liver failure [15].

The mechanisms involved in the development of IRI are not fully understood. It is a dynamic process consisting of oxidative stress mediated by reactive oxygen species (ROS) leading to pro-inflammatory responses and hepatic damage upon reperfusion [16]. Scavenging of ROS and radicals in ischemic tissues and simultaneous suppression of the activated inflammatory cascade may reduce IRI.

\subsection{Natural Remedies and Liver Protection}

Toxic effects of modern allopathic drugs prompted the search for alternatives. Medicinal plants are a key resource for drug extraction [17]. A number of natural compounds with hepatoprotective properties promising to be safe alternatives to allopathic drugs with less side effects were identified. Three well-characterized examples are the grape skin component resveratrol, green tea catechins (GTCs) and tetrandin, a bis-benzylisoquinoline alkaloid isolated from the medicinal herb Stephania tetrandra S Moore. They have been tested for their ability to suppress pro-inflammatory immune responses and/or oxidative stress in ischemic liver [18-20].

Trans-resveratrol given before ischemia and before reperfusion at low doses protects against IRI mainly through maintenance of glutathione (GSH) levels and induction of superoxide dismutase (SOD) and catalase (CAT) enzymes [20]. GTCs have antioxidant properties in a dose-dependent manner via maintenance of manganese superoxide dismutase (MnSOD) and suppression of inflammation [19]. The agent tetrandine is anti-inflammatory and blocks calcium-channels. Furthermore, it can reduce oxidative stress by maintaining SOD activity [18].

Yet, in many cases, the actual mechanism of liver protection remains unclear. The agents could act as direct antioxidants, indirectly through nuclear respiratory factor 2 (Nrf2) activation or through unrecognized mechanisms [21]. However, none of the substances was implemented into clinical routine for different reasons. First, the bioavailability of most secondary plant extracts is very low. Second, their activity highly depends on concentration with many having contradictory effects at different concentrations. For instance, resveratrol is a pro-oxidant and may lead to liver damage when given at a high dose [21,22].

A recent study highlighted the hepatoprotective effect of Antrodia cinnamomea, a fungus species, in carbon tetrachloride (CCI4) induced hepatic injury in rats. The animals were either orally treated with 
an Antrodia cinnamomea water extract once per day or an emulsified extract for 5 days. The emulsified extract at $50 \mathrm{mg} / \mathrm{kg}$ significantly decreased the serum alanine aminotransferase (ALT), aspartate aminotransferase (AST), interleukin-1 (IL-1), IL-6, nitric oxide (NO) and ROS levels. Additionally, cyclooxygenase-2 (COX-2) and caspase-3 protein expression was reduced [23]. This novel and intriguing data strengthens the need for further investigations in this field.

\subsection{Characterization of Nigella sativa Seeds, Its Oil and Its Active Components}

N. sativa (Family Ranunculaceae) is a good example for a natural compound with a variety of beneficial properties. The bisexual plant is $20-90 \mathrm{~cm}$ tall with finely divided leaves and blue flowers on solitary long peduncles. It forms a fruit capsule which opens up when matured to expose the white trigonal seeds to the air, which then become black in colour $[24,25]$.

N. sativa seeds contain numerous esters of unsaturated fatty acids with terpene alcohols. The currently known chemical composition of the seeds is depicted in Table 1.

The oil is one of the key components. An essential and a fixed oil can be extracted from the seeds [24-26]. The essential oil ranges from $0.4 \%$ to $2.5 \%$ [25,27]. It is cold-pressed from the seeds and is a yellow to dark amber liquid. The major active component in the essential oil is thymoquinone (2-isopropyl-5-methyl-1,4-benzoquinone) with up to $50 \%$, followed by p-cymene (40\%), pinene (up to $15 \%)$ and traces of thymohydroquinone and dithymoquinone.

The fixed oil (36-38\%) is produced by hydraulic expression of the seeds [26] and is rich in polyunsaturated fatty acids as well as some minor dihomolinolenic acids, phytosterols and tocopherols [28].

Alpha-hederin, a triterpene saponin, was also identified as an active component of N. sativa, but not much has been revealed about its amount in the seeds or its chemical stability. Further constituents of the seeds are unsaturated fatty acids, such as linoleic acid, oleic acid, eicodadienoic and dihomolinoleic acid. About $30 \%$ of the seeds consists of saturated fatty acids (stearic acid and palmitic acid) $[24,25,29]$.

Table 1. Composition of N. sativa seeds according to Mollazadeh et al. [25].

\begin{tabular}{cc}
\hline Constituent & \% Range \\
\hline Carbohydrates & $33-34$ \\
Oil & $31-35.5$ \\
Protein & $16-19.9$ \\
Fibre & $4.5-6.5$ \\
Moisture & $5-7$ \\
Saponins & 0.013 \\
\hline
\end{tabular}

\subsection{Properties of N. sativa}

N. sativa has a long tradition in the Middle East as a part of an overall holistic approach to health. Commonly known as black seed, N. sativa is native to Southern Europe, North Africa and Southwest Asia. It is cultivated in many countries in the world like the Middle Eastern Mediterranean region, South Europe, India, Pakistan, Syria, Turkey and Saudi Arabia [30].

The use is wide spread in various traditional medical systems like Unani-Tibb, Ayurveda, Chinese medicine and Siddha [24]. Among Muslims, it has been defined as an ultimate remedy for all diseases except death due to a Prophetic hadith.

Several in vitro and in-vivo studies were performed to assess the pharmacological effects of N. sativa seed and its oil [31-33]. Thymoquinone was identified as the active component causing most of the therapeutic effects [25,34] including antioxidant, anti-inflammatory, hepatoprotective, hypoglycemic, anti-hypertensive, analgesic, diuretic, anti-microbial, anti-parasitic, spasmolytic and bronchodilatative properties [34]. 


\subsection{Toxicity Studies on N. sativa and Metabolism of TQ}

N. sativa has a low profile of side effects and high $\mathrm{LD}_{50}$ values in experimental studies prove its safety [35-38].

In 1965, El-Dakhakhani reported the $\mathrm{LD}_{50}$ value of TQ as $10 \mathrm{mg} / \mathrm{kg}$ when intraperitoneally injected in rats [39]. Later, Mansour et al. indicated, that the $\mathrm{LD}_{50}$ value in mice intoxicated with CCI4 is even higher. They reported a $\mathrm{LD}_{50}$ dose of $90.3 \mathrm{mg} / \mathrm{kg}$ after intraperitoneal (ip) TQ application without specifying the cause of death [40]. In the same study, they did not observe any hepatotoxic effects when applying lower doses $(4,8,12.5,25$ and $50 \mathrm{mg} / \mathrm{kg}$ ) TQ. ALT, AST and lactate dehydrogenase (LDH) levels were not significantly elevated upon treatment [39-41]. This was confirmed in many other studies. Intraperitoneal TQ doses between 5 to $18 \mathrm{mg} / \mathrm{kg}$ were injected to mice and rats without side effects [40-45]. However, according to Mansour et al., the only dose that ameliorated hepatotoxicity of CCI4 was $12.5 \mathrm{mg} / \mathrm{kg}$ ip and side effects were reported at doses higher than $50 \mathrm{mg} / \mathrm{kg}$ ip (see Section 2.2) [40].

Badary et al. reported, that after oral TQ administration in healthy mice the $\mathrm{LD}_{50}$ value is even higher $(2400 \mathrm{mg} / \mathrm{kg})$. At high doses, signs of toxicity were hypoactivity and difficulty in respiration [38,46]. However, Al-Ali et al. described lower $\mathrm{LD}_{50}$ values after oral ingestion in mice $(870.9 \mathrm{mg} / \mathrm{kg})$ and in rats $(794.3 \mathrm{mg} / \mathrm{kg})$. The animals became more and more drowsy and dyspnoeic before death or they recovered after $24 \mathrm{~h}$. On autopsy, both in the mice and rats receiving lethal doses of TQ, the heart, lungs, liver and kidneys as well as the peritoneum were congested, without any apparent sign of damage or necrosis. Probably, the cause of death was hypotension ultimately leading to shock [35].

Overall, these studies reveal strikingly different results between intraperitoneal and oral TQ administration ( $>8$ to $>25$-fold difference in dose). The oral application seems to be better tolerated as signs of toxicity occurred after much higher doses than after intraperitoneal application.

According to Wang et al., this may be due to the fact that compounds with low intestinal absorption exhibit less toxicity in oral administration than in the injection route [47]. However, not much is revealed about the metabolism of TQ. Nagi et al. suggest, that TQ may undergo a reduction to dihydrothymoquinone [46]. This theory is strengthened by Mansour et al. They postulate that oral TQ may be transformed into less toxic metabolites in the gastrointestinal tract or into dihydrothymoquinone in the liver. In contrast, when intraperitoneally injected, a complete absorption of TQ into the systemic circulation occurs [40]. Khalife et al. proved, that TQ reacts with GSH, nicotinamide adenine dinucleotide (NADH) and nicotinamide adenine dinucleotide phosphate (NADPH) in physiological conditions. This induces the formation of glutathionyl-dihydrothymoquinone after rapid reaction with GSH and dihydrothymoquinone (DHTQ) after slow reaction time with NADH and NADPH. Interestingly, TQ showed lower scavenging activities than glutathionyl-dihydrothymoquinone and DHTQ. These results suggest, that the cellular antioxidant defense can possibly be modulated through the nonenzymatic metabolic activation of TQ [47].

\subsection{Objective}

Our systematic review aims for providing a comprehensive overview of in vivo experimental and human studies to explore the potential suitability of TQ for reducing hepatic injury in modern surgical treatment concepts.

\section{Results}

The search disclosed a total of 92 articles containing the keywords liver and TQ; 36 studies covering the period from 1999 to 2017 met our selection criteria (Figure 1). The majority of the studies derived from eastern countries (Table 2). 

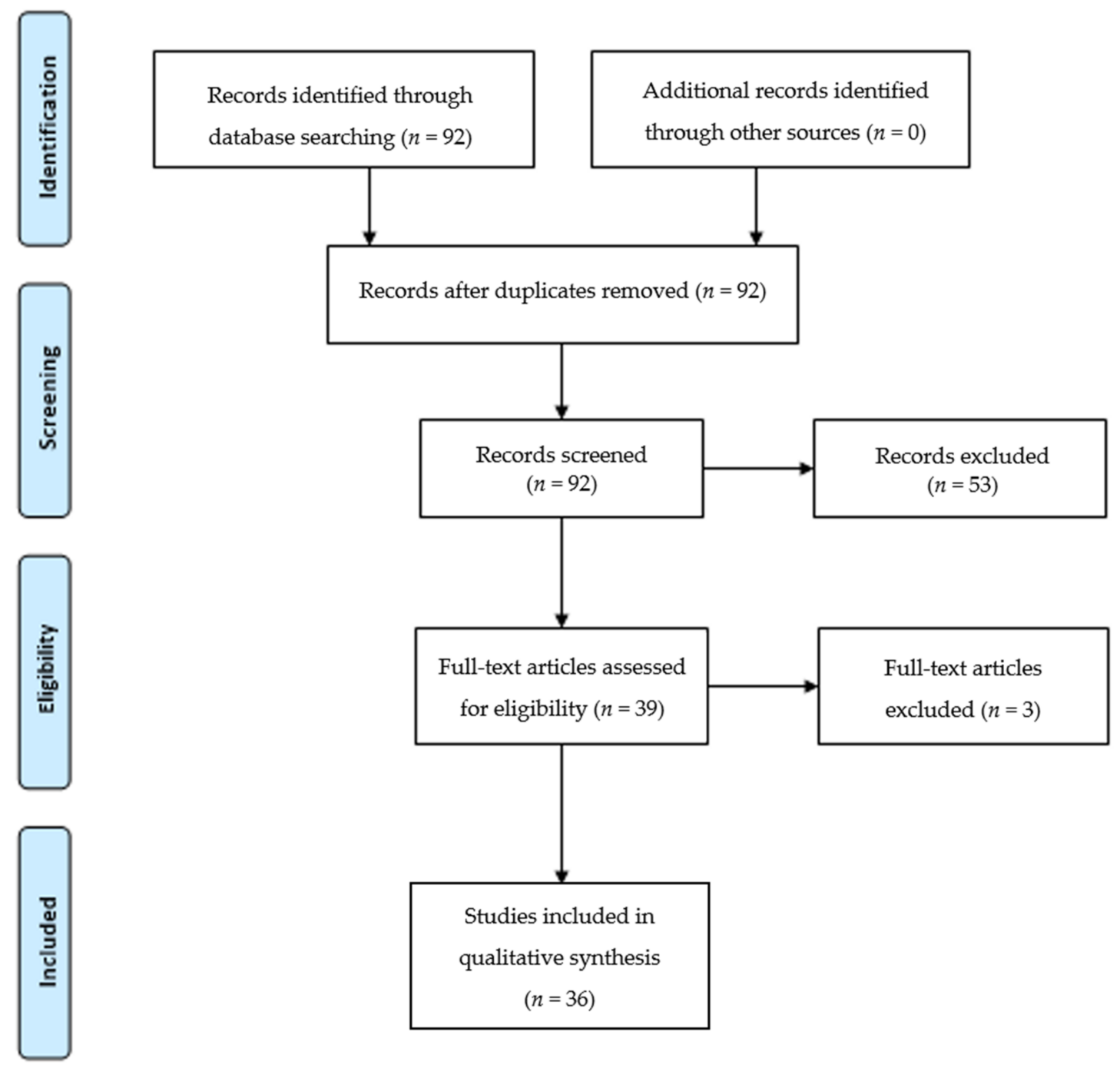

Figure 1. Assessment of eligible articles according to PRISMA 2009 Flow Diagram [48].

Table 2. Publication country of first authors and respective number of publications.

\begin{tabular}{cc}
\hline Country & $\boldsymbol{n}$ \\
\hline Saudi Arabia & 13 \\
China & 4 \\
Tunisia & 1 \\
Canada & 1 \\
Egypt & 7 \\
India & 2 \\
Malaysia & 1 \\
Iran & 1 \\
Turkey & 4 \\
USA & 2 \\
\hline
\end{tabular}

\subsection{Study Protocols and Applied TQ Doses}

We did not find any studies involving humans. The majority of the experiments were performed in rats $(n=24 ; 67 \%)$, followed by mice $(n=10 ; 28 \%)$ and rabbits $(n=2 ; 6 \%)$. 
The mainly synthetically manufactured TQ was purchased from chemical companies. In most studies, animals received TQ orally $(n=30 ; 83 \%)$. In five studies, TQ was administered intraperitoneally $(14 \%)$ and in one subcutaneously ( $3 \%)$.

A variety of injury models was used with the majority being hepatotoxic models using drugs such as cyclophosphamide, acetaminophen and methotrexate. Other models employed to investigate the hepatoprotective properties included steatosis, tumor, cholestasis, IRI, healthy animal and irradiation models (Table 3).

Table 3. Hepatic injury models applied in the experiments $(n=36)$.

\begin{tabular}{cccc}
\hline Model & $\boldsymbol{n}$ & $\mathbf{\%}$ & Corresponding Summary Table \\
\hline Toxic liver injury & 23 & 64 & Table 4 \\
Steatosis & 3 & 6 & Table 5 \\
Tumor & 3 & 8 & Table 6 \\
Cholestasis & 2 & 6 & Table 7 \\
IRI & 2 & 6 & Table 8 \\
Healthy liver & 2 & 6 & Table 9 \\
Irradiation & 1 & 3 & Table 10 \\
\hline
\end{tabular}

A wide range of doses was tested with a minimum of $0.5 \mathrm{mg} / \mathrm{kg} /$ day $[49,50]$ and a maximum of $100 \mathrm{mg} / \mathrm{kg} /$ day [46,49]. Only Mansour [40] et al. investigated the $\mathrm{LD}_{50}$ of TQ in mice intoxicated with CCI4 (see Section 1.5).

\subsection{Effect of $T Q$}

Our analysis revealed that all authors described a reduction of liver damage in TQ-treated animals, irrespective of the underlying etiology. Liver damage was assessed using histology and liver enzyme release. The beneficial effect was attributed to TQ having strong antioxidant, anti-inflammatory, antifibrotic, anti- and proapoptotic as well as anticarcinogenic effects (Tables 4-10, see Section 2.2.6).

Side effects were only reported in one study and consisted of oxidative stress leading to hepatic injury when higher doses of TQ (>50 mg/kg ip) were applied [40].

\subsubsection{TQ and Oxidative Stress}

The antioxidant effect was the most emphasized property of TQ. The majority of the results were achieved in liver toxicity models [40,41,43-46,50-61] and steatosis models [49,62,63], followed by tumor [64] (see Section 2.2.5), cholestasis [65,66], IRI [67,68], irradiation [69] and healthy liver models [70,71].

The liver injury consisted of severe alterations of the liver histology and in significant elevation of liver enzymes such as AST, ALT, ALP and $\gamma$-GT. These changes were mediated by an impaired antioxidant system revealed by up- or downregulation of selected oxidative stress markers. As a result of TQ administration, almost all authors reported an improvement of liver histology together with the reduction of liver enzymes. These results suggest that TQ interacts with oxidative stress markers to reinforce the antioxidant system. In detail, upon TQ application the reduction of GSH $[45,50,51,53,56-59,61,67]$ and $\mathrm{NO}[53,54,56,67]$ content, the inhibition of lipid peroxidase (LPO) $[43,44,46,51,52,61]$ as well as the downregulation of malondialdehyde (MDA) $[40,43,45,53,55-57,59,62,63]$ were observed.

\subsubsection{TQ and Inflammation}

In a variety of hepatic injury models, concomitant treatment with TQ led to a reduction of a wide range of different inflammatory markers as described in the following paragraphs.

The majority of the authors attributed an important role to the TQ-induced inactivation of the tumor necrosis factor- $\alpha$ (TNF- $\alpha$ ) cell signaling pathway. Within these authors, El-Sheikh et al. [56], 
Galaly et al. [72], Al-Malki et al. [53], Suddek et al. [61] and Hassanein et al. [58] performed their experiments on toxic hepatic injury models caused by drugs and chemicals, respectively Methotrexate, Gentamicin, Cisplatin, Tamoxifen and Titaniumdioxide nanoparticles. Helal et al. [59] provoked endotoxemia by lipopolysaccharide (LPS) application in the experimental animals. Awad et al. [62] applied a model of nonalcoholic steatohepatitis (NASH) induced by high-fat high-cholesterol diet. Beside the reduction of TNF- $\alpha$, El-Sheikh et al. also showed a lower level of COX-2 [56]. Al-Malki et al. attributed a further role to the reduction of IL-1 $\beta$ levels [53]. In their steatosis model, Awad et al. reported an increase in IL10 along with TNF- $\alpha$ reduction [62].

Further parameters that seem to be involved in the development of the anti-inflammatory effect of TQ were described by Aras et al. [54], Mohany et al. [44] and Abd-Elbaset et al. [67]. Both, Aras et al. and Mohany et al. applied toxicity models in which the injury was induced by Sodium arsenate (SA) and Imidacloprid, respectively. Abd-Elbaset al. created IRI models through occlusion of the hepatic pedicle for 30 minutes. Aras et al. attributed the favourable effects of TQ to the reduced expression of IL-6, monocyte chemotactic protein-1 (MCP-1) and migration inhibitory factor (MIF) [54]. Mohany et al. explained the improvements in liver histology and blood parameters by increased phagocytic activity, chemokinesis, chemotaxis and immunoglobulin (Ig) levels [44]. Abd-Elbaset et al. showed an association of the anti-inflammatory effects with a decreased myeloperoxidase (MPO) level [67].

\subsubsection{TQ and Fibrosis}

TQ reduces fibrosis. This was revealed by the normalization of histological changes and liver enzyme levels in toxicity and steatosis models upon application of TQ.

The authors Bai et al., Ghazwani et al. and Yang et al. mainly attributed the positive effect of TQ on fibrotic liver injury to the inhibition of transforming growth factor- $\beta$ (TGF- $\beta$ )-induced hepatic stellate cells (HSC) activation, the downregulation of $\alpha$-smooth muscle actin ( $\alpha$-SMA) expression and the activation of adenosine monophosphate-activated protein kinase (AMPK) phosphorylation [73-75]. The antifibrotic effect of TQ was furthermore associated with the downregulation of collagen-I as described by Bai et al. and Ghazwani et al. [73,74].

Abdelghany et al. attributed the TQ-induced inhibition of the progression of fibrosis in CCI4 toxicity models to the modulation of several fibrosis-related inflammatory mediators such as IL-6, IL-6R, IL-22, IL-22RA1+2, IL-10RA and IL-10RB. In addition, a decrease of TGF-B1 and TGF-BRII was analyzed [76].

Furthermore, a significant influence on the breakdown of the extracellular matrix through modulation of metalloproteinases was assigned to TQ. Three different ways were described: upregulation of matrix metallopeptidase 9 (MMP-9) [76], downregulation of tissue inhibitor of metalloproteinase-1 (TIMP-1) mRNA expression [73] and decrease of matrix metallo-proteinase-2 [62] which was observed in NASH-models.

\subsubsection{TQ and Apoptosis}

Seven authors described the effect of TQ on apoptosis. El-Sheikh et al. [56], Galaly et al. [72], Al-Malki et al. [53], Helal et al. [59], Yang et al. [75] and Ghazwani et al. [74] performed their experiments on chemically induced toxicity models. Awad et al. [62] used a steatosis model.

El-Sheikh et al., Galaly et al. and Helal et al. observed a decrease in caspase 3 expression suggesting lower levels of apoptosis $[56,59,72]$. The same effect was described by Yang et al., however through enhancement of sirtuin 1 (SIRT1) expression [75]. Pointing in the direction, Galaly et al. and Awad et al. have reported a further antiapoptotic effect via the normalization of proapoptotic Bax expression in cytoplasm and nucleus of hepatocytes as well as the increase of antiapoptotic B-cell lymphoma-2 (Bcl-2) level [62,72].

In contrast, El-Sheikh et al., Al-Malki et al. and Ghazwani et al. found low levels of nuclear factor kappa-B (NF-kB) expression, suggesting a proapoptotic effect $[53,56,74]$. 
To summarize, TQ modulates different mechanisms involved in apoptosis and thereby the analyzed effects of TQ apparently vary from anti- to proapoptotic. However, taking into account, that $\mathrm{NF}-\mathrm{KB}$ is also strongly involved in immune responses and the authors rather concentrated on this topic, the low NF-KB expression should be seen in the context of the anti-inflammatory effect of TQ which dominates the proapoptotic response.

\subsubsection{TQ and Hepatic Malignancy}

An important property of $\mathrm{TQ}$ is its direct and indirect anticarcinogenic effect in various tumor models. Our focus was on hepatic tumor models.

Ke X. et al. injected Hep3B cells subcutaneously in mice to create HCC models. They observed a normalization of the histology and a decrease of tumor volume when TQ was applied. This effect was explained by inhibition of Bcl-2 expression and repression of the Notch signaling pathway through downregulating NOTCH1 intracellular domain (NICD1). Furthermore, TQ inhibited cell growth by inducing cell cycle arrest through increased expression of p21 protein [77].

In N-nitrosodiethylamine (NDEA) induced HCC rats, Raghunandhakumar S. et al. reported that TQ greatly reduced liver injury markers, decreased tumor markers and prevented hepatic nodule formation through reduced neoplastic transformation of hepatocytes. Application of TQ had an anti-proliferative effect mediated by regulation of the G1/S phase cell cycle transition [78].

Sayed-Ahmed et al. also used NDEA-induced hepatocarcinogenesis models. Pathophysiologically, the initiation of hepatic cancer in these models is induced by decreased mRNA expression of GPx, CAT and GST. TQ application prevented the development of liver cancer by decreasing oxidative stress and preserving the activity and mRNA expression of antioxidant enzymes [64].

In conclusion, these promising properties of TQ can open new perspectives in liver cancer prevention and treatment.

2.2.6. Summary of the Hepatoprotective Effects of TQ in Tables 
Table 4. Effects on liver injury caused by intoxication

\begin{tabular}{|c|c|c|c|c|c|c|c|c|c|c|}
\hline & Injur & Model & TQ & & & & Effect of TQ & & & \\
\hline $\mathbf{R}$ & $\begin{array}{l}\cdot \text { Model } \\
\text { - Duration of } \\
\text { Induction } \\
\text { - Species }\end{array}$ & Toxic Effect & $\begin{array}{l}\cdot \text { Dose } \\
\cdot \text { Route of } \\
\text { Administration } \\
\cdot \text { Duration of } \\
\text { Treatment }\end{array}$ & $\begin{array}{l}\text { Reduction of } \\
\text { Hepatic Damage }\end{array}$ & $\begin{array}{l}\text { Anti- } \\
\text { Inflammatory }\end{array}$ & $\begin{array}{l}\text { Anti-/Pro- } \\
\text { Apoptotic }\end{array}$ & Antifibrotic & $\begin{array}{l}\text { Anti- } \\
\text { Carcinogenic }\end{array}$ & Anti-Oxidative & Others \\
\hline$[56]$ & $\begin{array}{l}\cdot \text { MTX } \\
\cdot \text { Single dose } \\
(20 \mathrm{mg} / \mathrm{kg} \text { ip }) \\
\text { day } 3 \\
\cdot \text { Rat }\end{array}$ & $\begin{array}{l}\text { Dilatation and } \\
\text { congestion of } \\
\text { portal vein }\end{array}$ & $\begin{array}{l}\cdot 10 \mathrm{mg} / \mathrm{kg} / \mathrm{d} \\
\cdot \text { po } \\
\cdot 10 \text { days }\end{array}$ & $\begin{array}{l}\text { - Normal hepatic } \\
\text { architecture }\end{array}$ & $\begin{array}{l}\cdot \downarrow \mathrm{TNF}-\alpha \\
\text { COX-2 }\end{array}$ & $\begin{array}{l}\cdot \downarrow \text { caspase } 3 \\
\cdot \downarrow \text { NF-kB } \\
\text { expression }\end{array}$ & & & $\begin{array}{l}\cdot \uparrow \mathrm{GSH} \\
\cdot \downarrow \mathrm{MDA}, \mathrm{NO}, \\
\text { iNOS }\end{array}$ & \\
\hline [54] & $\begin{array}{l}\cdot \text { SAs } \\
\cdot 14 \text { days } \\
\cdot \text { Rat }\end{array}$ & $\begin{array}{l}\cdot \text { Elevation of } \\
\text { liver enyzmes } \\
\cdot \downarrow \text { albumin }\end{array}$ & $\begin{array}{l}\cdot 10 \mathrm{mg} / \mathrm{kg} \mathrm{bw} \\
\cdot \text { po } \\
\cdot 14 \text { days }\end{array}$ & $\begin{array}{l}\cdot \downarrow \text { AST, ALT } \\
\cdot \uparrow \text { albumin }\end{array}$ & $\begin{array}{l}\downarrow \text { IL-6, } \\
\text { MCP-1 and } \\
\text { MIF }\end{array}$ & & & & $\cdot \downarrow \mathrm{NO}$ & $\begin{array}{l}\cdot \downarrow \mathrm{TG}, \\
\text { creatinine, } \\
\text { cholesterol }\end{array}$ \\
\hline [72] & $\begin{array}{l}\text { - Gentamicin } \\
\text { - } 21 \text { days } \\
\text { (every 2nd } \\
\text { day) } \\
\text { - Rat }\end{array}$ & $\begin{array}{l}\text { · Hydropic } \\
\text { degeneration of } \\
\text { hepatocytes, } \\
\text { fatty changes, } \\
\text { inflammatory } \\
\text { cell infiltration, } \\
\text { congestion of } \\
\text { portal vein } \\
\text { - Elevation of } \\
\text { liver enyzmes, } \\
\text { decrease of } \\
\text { proteins }\end{array}$ & $\begin{array}{l}\cdot 20 \mathrm{mg} / \mathrm{kg} \text { bw } \\
\cdot \text { po } \\
\cdot 21 \text { days (every } \\
2 \text { nd day) }\end{array}$ & $\begin{array}{l}\cdot \text { Normal hepatic } \\
\text { architecture } \\
\cdot \downarrow \text { AST, ALT, } \\
\text { LDH, total } \\
\text { bilirubin level } \\
\text { · improvement of } \\
\text { serum total } \\
\text { protein, albumin } \\
\text { and albumin/ } \\
\text { globulin ratio }\end{array}$ & $\cdot \downarrow$ TNF- $\alpha$ & $\begin{array}{l}\cdot \text { Caspase } 3 \\
\text { and Bax } \\
\text { expression } \\
\text { reduced to } \\
\text { normal } \\
\cdot \uparrow \text { Bcl-2 }\end{array}$ & & & & \\
\hline [53] & $\begin{array}{l}\text { - Cisplatin } \\
\text { - Single } \\
\text { injection }(12 \\
\mathrm{mg} / \mathrm{kg} \text { ip) at } \\
\text { day } 28 \\
\text { - Rat }\end{array}$ & $\begin{array}{l}\text { - Elevation of } \\
\text { liver parameters } \\
\text { - Vacuolar } \\
\text { degeneration } \\
\text { and } \\
\text { hepatocellular } \\
\text { necrosis }\end{array}$ & $\begin{array}{l}\cdot 10 \mathrm{mg} / \mathrm{kg} / \mathrm{d} \\
\cdot \text { po } \\
\cdot 28 \text { days } \\
\text { pretreatment }+ \\
28 \text { days after } \\
\text { Cisplatin }\end{array}$ & $\begin{array}{l}\cdot \text { Normal hepatic } \\
\text { architecture } \\
\cdot \downarrow \text { AST, ALT, ALP, } \\
\gamma \text {-GT, total } \\
\text { bilirubin, LDH }\end{array}$ & $\begin{array}{l}\cdot \downarrow \mathrm{TNF}-\alpha \\
\text { and IL-1 } \beta\end{array}$ & $\begin{array}{l}\cdot \downarrow N F-k B \\
\text { expression }\end{array}$ & & & $\begin{array}{l}\cdot \uparrow \mathrm{Gpx}, \mathrm{GSH}, \\
\text { SOD, GST, } \\
\text { CAT } \\
\cdot \downarrow \mathrm{MDA}, \mathrm{NO}\end{array}$ & \\
\hline
\end{tabular}


Table 4. Cont

\begin{tabular}{|c|c|c|c|c|c|c|c|c|c|c|}
\hline & Injur & Model & TQ & & & & Effect of TQ & & & \\
\hline $\mathbf{R}$ & $\begin{array}{l}\text { - Model } \\
\text { - Duration of } \\
\text { Induction } \\
\text { - Species }\end{array}$ & Toxic Effect & $\begin{array}{l}\cdot \text { Dose } \\
\cdot \text { Route of } \\
\text { Administration } \\
\cdot \text { Duration of } \\
\text { Treatment }\end{array}$ & $\begin{array}{l}\text { Reduction of } \\
\text { Hepatic Damage }\end{array}$ & $\begin{array}{l}\text { Anti- } \\
\text { Inflammatory }\end{array}$ & $\begin{array}{l}\text { Anti-/Pro- } \\
\text { Apoptotic }\end{array}$ & Antifibrotic & $\begin{array}{l}\text { Anti- } \\
\text { Carcinogenic }\end{array}$ & Anti-Oxidative & Others \\
\hline$[61]$ & $\begin{array}{l}\cdot \text { Tamoxifen } \\
\cdot 10 \text { days (45 } \\
\mathrm{mg} / \mathrm{kg} / \mathrm{d} \text { ip) } \\
\text { - Rat }\end{array}$ & $\begin{array}{l}\text { - Elevation of } \\
\text { liver parameters }\end{array}$ & $\begin{array}{l}\cdot 50 \mathrm{mg} / \mathrm{kg} / \mathrm{d} \\
\cdot \text { po } \\
\cdot 20 \text { days, } \\
\text { starting } 10 \text { days } \\
\text { before } \\
\text { intoxication }\end{array}$ & $\begin{array}{l}\cdot \downarrow \text { AST, ALT, } \\
\text { LDH, total } \\
\text { bilirubin and } \\
\gamma \text {-GT }\end{array}$ & $\cdot \downarrow$ TNF- $\alpha$ & & & & $\begin{array}{l}\cdot \text { Normalizing } \\
\text { SOD activity } \\
\cdot \downarrow \text { GSH, LPO }\end{array}$ & \\
\hline$[44]$ & $\begin{array}{l}\cdot \text { Imidacloprid } \\
\cdot 28 \text { days }(0.21 \\
\mathrm{mg} / \mathrm{kg} \text { bw po) } \\
\cdot \text { Rat }\end{array}$ & $\begin{array}{l}\text { Congestion of } \\
\text { central vein and } \\
\text { blood sinusoids, } \\
\text { widely } \\
\text { distributed } \\
\text { pyknotic nuclei } \\
\text { and leukocyte } \\
\text { infiltration } \\
\text { - Elevation of } \\
\text { liver enzymes }\end{array}$ & $\begin{array}{l}\cdot 1 \mathrm{mg} / \mathrm{kg} \\
\cdot \text { ip } \\
\cdot 28 \text { days (every } \\
7 \text { th day) }\end{array}$ & $\begin{array}{l}\cdot \text { Improved } \\
\text { hepatic } \\
\text { architecture } \\
\cdot \downarrow \text { AST, ALT, ALP }\end{array}$ & $\begin{array}{l}\cdot \uparrow \\
\text { phagocyte } \\
\text { activity, } \\
\text { chemokinesis, } \\
\text { chemotaxis, } \\
\text { total levels } \\
\text { of Ig }\end{array}$ & & & & $\begin{array}{l}\text { Inhibition of } \\
\text { LPO }\end{array}$ & \\
\hline [59] & $\begin{array}{l}\cdot \text { LPS } \\
\text { Single dose } \\
\text { at day } 6 \\
\cdot \text { Rat }\end{array}$ & $\begin{array}{l}\text { - Infiltration of } \\
\text { inflammatory } \\
\text { cells along with } \\
\text { necrotic } \\
\text { Damages } \\
\text { Elevation of } \\
\text { liver enzymes }\end{array}$ & $\begin{array}{l}\cdot 10 \mathrm{mg} / \mathrm{kg} / \mathrm{d} \\
\cdot \text { po } \\
\cdot 7 \text { days }\end{array}$ & $\begin{array}{l}\cdot \text { Reduced } \\
\text { infiltration of } \\
\text { inflammatory } \\
\text { cells and necrotic } \\
\text { damage } \\
\cdot \downarrow \text { total bilirubin, } \\
\text { ALP, } \gamma \mathrm{GT}\end{array}$ & $\cdot \downarrow$ TNF- $\alpha$ & $\cdot \downarrow$ caspase 3 & & & $\begin{array}{l}\cdot \\
\text { of GSH level } \\
\cdot \downarrow \text { MDA }\end{array}$ & \\
\hline [75] & $\begin{array}{l}\cdot \text { Ethanol } \\
\cdot 10 \text { days } 5 \% \\
\text { Vol., at day } 11 \\
5 \mathrm{~g} / \mathrm{kg} \text { po } \\
\cdot \text { Rat }\end{array}$ & $\begin{array}{l}\text { - Hepatocyte } \\
\text { enlargement, } \\
\text { steatosis, } \\
\text { inflammation } \\
\text { - Elevation of } \\
\text { liver enzymes }\end{array}$ & $\begin{array}{l}\cdot 20 \& 40 \mathrm{mg} / \mathrm{kg} \\
\cdot \text { po } \\
\cdot 10 \text { days }\end{array}$ & $\begin{array}{l}\cdot \text { Reduction of } \\
\text { histological } \\
\text { changes } \\
\cdot \downarrow \text { ALT, AST }\end{array}$ & & $\begin{array}{l}\text { Enhancement } \\
\text { of sirtuin } 1 \\
\text { (SIRT1) } \\
\text { expression }\end{array}$ & $\begin{array}{l}\cdot \text { Activation } \\
\text { of LKB1 and } \\
\text { AMPK } \\
\text { phosphorylation } \\
\cdot \text { Inhibition } \\
\text { of TGF- } \beta \\
\text { induced } \\
\text { HSC } \\
\text { activation }\end{array}$ & & & $\cdot \downarrow \mathrm{TG}$ \\
\hline
\end{tabular}


Table 4. Cont

\begin{tabular}{|c|c|c|c|c|c|c|c|c|c|c|}
\hline & \multicolumn{2}{|c|}{ Injury Model } & \multirow{2}{*}{\begin{tabular}{l}
\multicolumn{1}{c}{ TQ } \\
- Dose \\
- Route of \\
Administration \\
· Duration of \\
Treatment
\end{tabular}} & \multicolumn{7}{|c|}{ Effect of TQ } \\
\hline $\mathbf{R}$ & $\begin{array}{l}\cdot \text { Model } \\
\cdot \text { Duration of } \\
\text { Induction } \\
\cdot \text { Species }\end{array}$ & Toxic Effect & & $\begin{array}{l}\text { Reduction of } \\
\text { Hepatic Damage }\end{array}$ & $\begin{array}{l}\text { Anti- } \\
\text { Inflammatory }\end{array}$ & $\begin{array}{l}\text { Anti-/Pro- } \\
\text { Apoptotic }\end{array}$ & Antifibrotic & $\begin{array}{l}\text { Anti- } \\
\text { Carcinogenic }\end{array}$ & Anti-Oxidative & Others \\
\hline [40] & $\begin{array}{l}\cdot \text { CCI4 } \\
\cdot \text { Single } \\
\text { injection } \\
(15 \mu \mathrm{L} / \mathrm{kg} \text { ip }) \\
\cdot \text { Mouse }\end{array}$ & $\begin{array}{l}\text { - Elevation of } \\
\text { liver enyzmes }\end{array}$ & $\begin{array}{l}\cdot 4,8,12.5,25 \& \\
50 \mathrm{mg} / \mathrm{kg} \\
\cdot \text { ip } \\
\cdot \text { pretreatment } 1 \\
\mathrm{~h} \text { before CCI } 4 \\
\text { injection }\end{array}$ & $\cdot \downarrow \mathrm{AST}, \mathrm{ALT}, \mathrm{LDH}$ & & & & & $\begin{array}{l}\cdot \downarrow \text { MDA } \\
\cdot \uparrow \text { nonprotein } \\
\text { sulfhydryl } \\
\text { (-SH) } \\
\text { concentration }\end{array}$ & \\
\hline$[74]$ & $\begin{array}{l}\cdot \text { CCI4 } \\
\cdot \text { Single dose } \\
\text { on day } 6 \\
\cdot \text { Mouse }\end{array}$ & $\begin{array}{l}\cdot \text { Not specified } \\
\text { histological } \\
\text { changes }\end{array}$ & $\begin{array}{l}\cdot 25 \mathrm{mg} / \mathrm{kg} / \mathrm{d} \\
\cdot \text { po } \\
\cdot 7 \text { days }\end{array}$ & $\begin{array}{l}\text { Significant } \\
\text { resistance to liver } \\
\text { damage (not } \\
\text { specified) }\end{array}$ & & $\begin{array}{l}\text { Inactivation } \\
\text { of NF-kB } \\
\text { pathway }\end{array}$ & $\begin{array}{l}\cdot \text { Inhibition } \\
\text { of } \\
\text { upregulation } \\
\text { of COL1A1 } \\
\text { mRNA } \\
\text { expression } \\
\cdot \text { Inhibition } \\
\text { of HSCs } \\
\cdot \downarrow \alpha \text {-SMA }\end{array}$ & & & \\
\hline [76] & $\begin{array}{l}\cdot \text { CCI } 4 \\
\cdot 3 \mu \mathrm{L} / \mathrm{g} \text { twice } \\
\text { weekly for } 49 \\
\text { days } \\
\text {. Rat }\end{array}$ & $\begin{array}{l}\text { Cellular } \\
\text { infiltration and } \\
\text { fibrous septa } \\
\text { - Elevation of } \\
\text { liver enyzmes }\end{array}$ & $\begin{array}{l}\cdot 35 \mathrm{mg} / \mathrm{kg} / \mathrm{d} \\
\cdot \text { po } \\
\cdot 3 \mathrm{x} / \text { week from } \\
\text { day } 63 \text { to } 119\end{array}$ & $\begin{array}{l}\cdot \text { Less histological } \\
\text { changes } \\
\cdot \downarrow \text { ALT, AST }\end{array}$ & & & $\begin{array}{l}\cdot \downarrow \text { TGF-131, } \\
\text { IL-6, IL-22, } \\
\text { TGF-BRII, } \\
\text { IL-6R, } \\
\text { IL-22RA1+2, } \\
\text { IL-10RA, } \\
\text { IL-10RB } \\
\cdot \uparrow \text { MMP9 } \\
\text { mRNA }\end{array}$ & & & \\
\hline [43] & $\begin{array}{l}\cdot \text { CCI4 } \\
\text { Single } \\
\text { injection } \\
(20 \mu \mathrm{L} / \mathrm{kg} \text { ip) } \\
\cdot \text { Mouse }\end{array}$ & $\begin{array}{l}\text { - Elevation of } \\
\text { liver enyzmes }\end{array}$ & $\begin{array}{l}\cdot 16 \mathrm{mg} / \mathrm{kg} / \mathrm{d} \\
\cdot \text { po } \\
\cdot 1 \text { day (5 days } \\
\text { before } \\
\text { CCI4 injection) }\end{array}$ & $\cdot \downarrow$ ALT, AST, LDH & & & & & $\begin{array}{l}\cdot \uparrow \text { total SH } \\
\text { content } \\
\cdot \downarrow \text { MDA } \\
\cdot \text { Inhibition of } \\
\text { LPO }\end{array}$ & \\
\hline
\end{tabular}


Table 4. Cont.

\begin{tabular}{|c|c|c|c|c|c|c|c|c|c|c|}
\hline & \multicolumn{2}{|c|}{ Injury Model } & \multirow{2}{*}{\begin{tabular}{l}
\multicolumn{1}{c}{ TQ } \\
- Dose \\
· Route of \\
Administration \\
- Duration of \\
Treatment
\end{tabular}} & \multicolumn{7}{|c|}{ Effect of TQ } \\
\hline $\mathbf{R}$ & $\begin{array}{l}\text { - Model } \\
\cdot \text { Duration of } \\
\text { Induction } \\
\text { - Species }\end{array}$ & Toxic Effect & & $\begin{array}{l}\text { Reduction of } \\
\text { Hepatic Damage }\end{array}$ & $\begin{array}{l}\text { Anti- } \\
\text { Inflammatory }\end{array}$ & $\begin{array}{l}\text { Anti-/Pro- } \\
\text { Apoptotic }\end{array}$ & Antifibrotic & $\begin{array}{l}\text { Anti- } \\
\text { Carcinogenic }\end{array}$ & Anti-Oxidative & Others \\
\hline [46] & $\begin{array}{l}\cdot \text { CCI } 4 \\
\cdot \text { Single } \\
\text { injection } \\
(20 \mu \mathrm{L} / \mathrm{kg} \mathrm{ip}) \\
\cdot \text { Mouse }\end{array}$ & $\begin{array}{l}\text { - Elevation of } \\
\text { ALT }\end{array}$ & $\begin{array}{l}\cdot 100 \mathrm{mg} / \mathrm{kg} \\
\cdot \text { po } \\
\cdot 1 \text { day }\end{array}$ & $\cdot \downarrow$ ALT & & & & & $\begin{array}{l}\text { - Inhibition of } \\
\text { LPO }\end{array}$ & \\
\hline [73] & $\begin{array}{l}\text { Thiocetamide } \\
\cdot 3 x / \text { week for } \\
35 \text { days } \\
\cdot \text { Mouse }\end{array}$ & $\begin{array}{l}\text { - Necrosis, } \\
\text { collagen } \\
\text { deposition and } \\
\text { infiltration of } \\
\text { inflammatory } \\
\text { cells in liver } \\
\text { interstitial } \\
\text { - Elevation of } \\
\text { liver enyzmes }\end{array}$ & $\begin{array}{l}\cdot 10 \& 40 \mathrm{mg} / \mathrm{kg} \\
\cdot \text { po } \\
\cdot 35 \text { days }\end{array}$ & $\begin{array}{l}\cdot \text { Less liver } \\
\text { damage, } \\
\text { inflammatory cell } \\
\text { infiltration, } \\
\text { collagen-I and } \\
\alpha \text {-SMA positive } \\
\text { cells } \\
\cdot \downarrow \text { ALT, AST }\end{array}$ & & & $\begin{array}{l}\cdot \downarrow \text { protein } \\
\text { and mRNA } \\
\text { expression } \\
\text { of } \alpha \text {-SMA, } \\
\text { collagen-I, } \\
\text { TIMP-1 } \\
\cdot \text { AMK } \\
\text { phosphorylation }\end{array}$ & & & \\
\hline [52] & $\begin{array}{l}\text { Cyclophos- } \\
\text { Phamide } \\
\cdot 2 \text { injections } \\
\text { (200 mg/kg ip) } \\
\cdot \text { Rat }\end{array}$ & $\begin{array}{l}\text { Elevation of } \\
\text { liver parameters }\end{array}$ & $\begin{array}{l}\cdot 10 \mathrm{mg} / \mathrm{kg} / \mathrm{d} \\
\cdot \text { po } \\
\cdot 12 \text { days (every } \\
2 \text { nd day) }\end{array}$ & $\begin{array}{l}\cdot \downarrow \text { ALT, AST, } \\
\text { bilirubin, } \gamma \text {-GT }\end{array}$ & & & & & $\cdot \downarrow \mathrm{LPO}$ & $\begin{array}{l}\cdot \downarrow \text { urea, } \\
\text { creatinine, } \\
\text { TG, LDL, } \\
\text { cholesterol }\end{array}$ \\
\hline [41] & $\begin{array}{l}\text { Cyclophos- } \\
\text { phamide } \\
\cdot \text { Single dose } \\
\text { (250 mg/kg ip) } \\
\cdot \text { Mouse }\end{array}$ & $\begin{array}{l}\text { Severe } \\
\text { hemorrhage, } \\
\text { necrosis, } \\
\text { dilatation of } \\
\text { blood vessels } \\
\text { - Elevation of } \\
\text { liver parameters }\end{array}$ & $\begin{array}{l}\cdot 5 \& 10 \\
\mathrm{mSg} / \mathrm{kg} / \mathrm{d} \\
\cdot \mathrm{ip} \\
\cdot 3 \text { days }\end{array}$ & $\begin{array}{l}\cdot \text { Less hemorrhage } \\
\text { and necrosis } \\
\cdot \downarrow \text { ALT, AST, } \\
\text { bilirubin }\end{array}$ & & & & & $\cdot \uparrow \mathrm{SOD}, \mathrm{CAT}$ & \\
\hline
\end{tabular}


Table 4. Cont.

\begin{tabular}{|c|c|c|c|c|c|c|c|c|c|c|}
\hline & Injury & Model & TQ & & & & Effect of TQ & & & \\
\hline $\mathbf{R}$ & $\begin{array}{l}\cdot \text { Model } \\
\text { - Duration of } \\
\text { Induction } \\
\cdot \text { Species }\end{array}$ & Toxic Effect & $\begin{array}{l}\cdot \text { Dose } \\
\cdot \text { Route of } \\
\text { Administration } \\
\text { - Duration of } \\
\text { Treatment }\end{array}$ & $\begin{array}{l}\text { Reduction of } \\
\text { Hepatic Damage }\end{array}$ & $\begin{array}{l}\text { Anti- } \\
\text { Inflammatory }\end{array}$ & $\begin{array}{l}\text { Anti-/Pro- } \\
\text { Apoptotic }\end{array}$ & Antifibrotic & $\begin{array}{l}\text { Anti- } \\
\text { Carcinogenic }\end{array}$ & Anti-Oxidative & Others \\
\hline [45] & $\begin{array}{l}\cdot \text { Aflatoxin B } \\
\text { - Single dose } \\
\text { (2 mg/kg ip) } \\
\cdot \text { Mouse }\end{array}$ & $\begin{array}{l}\text { - Inflammation, } \\
\text { necrosis and } \\
\text { hyperlasia of } \\
\text { Kupffer cells, } \\
\text { infiltration of } \\
\text { mononuclear } \\
\text { cells, dilatation } \\
\text { of sinusoids and } \\
\text { disruption of } \\
\text { hepatocytes } \\
\text { - Elevation of } \\
\text { liver enyzmes }\end{array}$ & $\begin{array}{l}\cdot 4,5,9 \& 18 \\
\mathrm{mg} / \mathrm{kg} \\
\cdot \mathrm{ip} \\
\cdot 3 \text { days } \\
\text { pretreatment }\end{array}$ & $\begin{array}{l}\cdot \text { Improvement of } \\
\text { histological } \\
\text { changes } \\
\cdot \downarrow \text { AST, ALT, ALP }\end{array}$ & & & & & $\begin{array}{l}\cdot \downarrow \mathrm{MDA} \\
\cdot \text { recovering } \\
\text { GSH content }\end{array}$ & \\
\hline [60] & $\begin{array}{l}\cdot \text { Lead } \\
\cdot 35 \text { days } \\
\cdot \text { Rat }\end{array}$ & $\begin{array}{l}\text { Degenerative } \\
\text { changes in liver } \\
\text { cell architecture } \\
\text { - Elevation of } \\
\text { liver paramters }\end{array}$ & $\begin{array}{l}\cdot 5 \mathrm{mg} / \mathrm{kg} / \mathrm{d} \\
\cdot \text { po } \\
\cdot 35 \text { days }\end{array}$ & $\begin{array}{l}\cdot \text { Prevention of } \\
\text { histological } \\
\text { changes } \\
\cdot \downarrow \text { ALT, AST, ALP, } \\
\gamma \text {-GT }\end{array}$ & & & & & $\cdot \uparrow$ TAS level & \\
\hline [58] & $\begin{array}{l}\text { Titanium-dioxide } \\
\text { nanoparticles } \\
\cdot 42 \text { days } \\
\cdot \text { Rat }\end{array}$ & $\begin{array}{l}\text { Congestion, } \\
\text { necrosis and } \\
\text { mononuclear } \\
\text { infiltration } \\
\text { Elevation of } \\
\text { liver enzymes }\end{array}$ & $\begin{array}{l}\cdot 20 \mathrm{mg} / \mathrm{kg} \\
\cdot \text { po } \\
\cdot 42 \text { days }\end{array}$ & $\cdot \downarrow \mathrm{ALT}$ & $\cdot \downarrow \mathrm{TNF} \alpha$ & & & & $\begin{array}{l}\cdot \downarrow \text { oxidative } \\
\text { stress, DNA } \\
\text { damage } \\
\cdot \uparrow \text { TAS and } \\
\text { GSH levels }\end{array}$ & \\
\hline [55] & $\begin{array}{l}\text { Acet-Aminophen } \\
\text { - Single dose } \\
(500 \mathrm{mg} / \mathrm{kg} \\
\text { po) } \\
\text { - Rat }\end{array}$ & $\begin{array}{l}\text { Hepatic cell } \\
\text { necrosis and } \\
\text { toxicity } \\
\cdot \text { Elevation of } \\
\text { liver enyzmes }\end{array}$ & $\begin{array}{l}\cdot 15 \mathrm{mg} / \mathrm{kg} / \mathrm{d} \\
\cdot \text { po } \\
\cdot 1 \text { day }\end{array}$ & $\begin{array}{l}\cdot \text { Less necrosis } \\
\cdot \downarrow \text { ALT, AST }\end{array}$ & & & & & $\begin{array}{l}\cdot \uparrow \text { Gpx } \\
\cdot \downarrow \text { GSSG \& } \\
\text { SOD activity, } \\
\text { serum and } \\
\text { tissue MDA } \\
\text { levels }\end{array}$ & \\
\hline
\end{tabular}


Table 4. Cont.

\begin{tabular}{|c|c|c|c|c|c|c|c|c|c|c|}
\hline & \multicolumn{2}{|c|}{ Injury Model } & \multirow{2}{*}{\begin{tabular}{l}
\multicolumn{1}{c}{ TQ } \\
$\cdot$ Dose \\
$\cdot$ Route of \\
Administration \\
- Duration of \\
Treatment
\end{tabular}} & \multicolumn{7}{|c|}{ Effect of TQ } \\
\hline $\mathbf{R}$ & $\begin{array}{l}\text { - Model } \\
\text { - Duration of } \\
\text { Induction } \\
\text { - Species }\end{array}$ & Toxic Effect & & $\begin{array}{l}\text { Reduction of } \\
\text { Hepatic Damage }\end{array}$ & $\begin{array}{l}\text { Anti- } \\
\text { Inflammatory }\end{array}$ & $\begin{array}{l}\text { Anti-/Pro- } \\
\text { Apoptotic }\end{array}$ & Antifibrotic & $\begin{array}{l}\text { Anti- } \\
\text { Carcinogenic }\end{array}$ & Anti-Oxidative & Others \\
\hline [50] & $\begin{array}{l}\text { Acet-Aminophen } \\
\cdot \text { Single } \\
\text { injection ( } 500 \\
\mathrm{mg} / \mathrm{kg} \mathrm{ip}) \\
\cdot \text { Mouse }\end{array}$ & $\begin{array}{l}\text { Elevation of } \\
\text { ALT }\end{array}$ & $\begin{array}{l}\cdot 0.5,1 \& 2 \\
\mathrm{mg} / \mathrm{kg} / \mathrm{d} \\
\cdot \mathrm{po} \\
\cdot 5 \text { days }\end{array}$ & $\cdot \downarrow$ ALT & & & & & $\begin{array}{l}\cdot \downarrow \text { lipid } \\
\text { peroxide, GSH }\end{array}$ & $\begin{array}{l}\cdot \downarrow \text { total } \\
\text { nitrate/ } \\
\text { nitrite, ATP }\end{array}$ \\
\hline [51] & $\begin{array}{l}\cdot \text { Bisphenol A } \\
\text { - } 28 \text { days } \\
\text { - Rat }\end{array}$ & $\begin{array}{l}\text { Elevation of } \\
\text { liver parameters }\end{array}$ & $\begin{array}{l}\cdot 10 \mathrm{mg} / \mathrm{kg} \\
\cdot \text { po } \\
\cdot 35 \text { days }\end{array}$ & $\begin{array}{l}\cdot \downarrow \text { AST, ALT, ALP, } \\
\gamma \text {-GT and level of } \\
\text { total bilirubin }\end{array}$ & & & & & $\begin{array}{l}\cdot \downarrow \text { LPO } \\
\text { normalization } \\
\text { of TAS, GSH, } \\
\text { Gpx, GST, } \\
\text { SOD, CAT }\end{array}$ & $\begin{array}{l}\cdot \downarrow \text { total } \\
\text { cholesterol } \\
\cdot \downarrow \text { TG, LDL } \\
\text { and vLDL } \\
\cdot \uparrow \text { HDL }\end{array}$ \\
\hline [57] & $\begin{array}{l}\cdot \text { Chronic CsA } \\
\text { treatment } \\
\cdot 28 \text { days } \\
\cdot \text { Rat }\end{array}$ & $\begin{array}{l}\text { Central vein } \\
\text { congestion, } \\
\text { hepatocyte } \\
\text { vaculation, } \\
\text { portal } \\
\text { inflammation } \\
\text { and fibrosis } \\
\text { with bile } \\
\text { ductular } \\
\text { proliferation } \\
\text { and focal } \\
\text { necrosis } \\
\text { Elevation of } \\
\text { liver enyzmes }\end{array}$ & $\begin{array}{l}\cdot 10 \mathrm{mg} / \mathrm{kg} \\
\cdot \text { po } \\
\cdot 28 \text { days }\end{array}$ & $\begin{array}{l}\cdot \text { Mild congestion } \\
\text { of central vein } \\
\text { and sinuses with } \\
\text { minimal fibrotic } \\
\text { spots } \\
\cdot \downarrow \text { AST, ALT }\end{array}$ & & & & & $\begin{array}{l}\cdot \uparrow \mathrm{GSH}, \mathrm{SOD} \\
\cdot \downarrow \mathrm{MDA}\end{array}$ & \\
\hline
\end{tabular}


Table 5. Effects on liver injury caused by steatosis.

\begin{tabular}{|c|c|c|c|c|c|c|c|c|c|c|}
\hline & \multicolumn{2}{|c|}{ Injury Model } & \multirow{2}{*}{\begin{tabular}{l}
\multicolumn{1}{c}{ TQ } \\
· Dose \\
· Route of \\
Administration \\
· Duration of \\
Treatment
\end{tabular}} & \multicolumn{7}{|c|}{ Effect of TQ } \\
\hline $\mathbf{R}$ & $\begin{array}{l}\text { - Model } \\
\text { - Duration } \\
\text { of Induction } \\
\text { - Species }\end{array}$ & Toxic Effect & & $\begin{array}{l}\text { Reduction of } \\
\text { Hepatic Damage }\end{array}$ & $\begin{array}{l}\text { Anti- } \\
\text { Inflammatory }\end{array}$ & $\begin{array}{l}\text { Anti-/Pro- } \\
\text { Apoptotic }\end{array}$ & Antifibrotic & $\begin{array}{l}\text { Anti- } \\
\text { Carcinogenic }\end{array}$ & $\begin{array}{l}\text { Anti- } \\
\text { Oxidative }\end{array}$ & Others \\
\hline [49] & $\begin{array}{l}\text { - Hyper- } \\
\text { Cholesterolemia } \\
\text { (cholesterol diet) } \\
\cdot 56 \text { days } \\
\cdot \text { Rat }\end{array}$ & $\begin{array}{l}\text { - Elevation of } \\
\text { liver parameters }\end{array}$ & $\begin{array}{l}\cdot 20,50 \& 100 \\
\mathrm{mg} / \mathrm{kg} \text { bw } \\
\cdot \text { po } \\
\cdot 56 \text { days }\end{array}$ & $\cdot \downarrow \mathrm{ALT}, \gamma-\mathrm{GT}$ & & & & & $\begin{array}{l}\cdot \text { inhibition } \\
\text { of OH } \\
\cdot \uparrow \text { SOD1, } \\
\text { CAT, Gpx }\end{array}$ & $\begin{array}{l}\cdot \downarrow \text { plasma } \\
\text { total } \\
\text { cholesterol, } \\
\text { LDL } \\
\text { cholesterol, } \\
\text { creatinine, } \\
\text { urea }\end{array}$ \\
\hline$[62]$ & $\begin{array}{l}\cdot \text { NASH } \\
\text { (cholesterol diet) } \\
\cdot 42 \text { days } \\
\cdot \text { Rat }\end{array}$ & $\begin{array}{l}\text { Focal hepatic } \\
\text { necrosis, } \\
\text { vacuolation of } \\
\text { hepatocytes } \\
\text { associated with } \\
\text { portal } \\
\text { infiltration with } \\
\text { inflammatory } \\
\text { cells } \\
\text { - Elevation of } \\
\text { liver enyzmes }\end{array}$ & $\begin{array}{l}\cdot 10 \& 20 \\
\mathrm{mg} / \mathrm{kg} / \mathrm{d} \\
\cdot \mathrm{po} \\
\cdot 42 \text { days }\end{array}$ & $\begin{array}{l}\text { TQ } 10 \mathrm{mg} / \mathrm{kg} / \text { day: } \\
\text { few inflammatory } \\
\text { cells infiltration in } \\
\text { between the few } \\
\text { fatty changed } \\
\text { hepatocytes } \\
\cdot \text { TQ } 20 \mathrm{mg} / \mathrm{kg} / \text { day: } \\
\text { slight congestion of } \\
\text { hepatic sinusoids } \\
\text { and minimal } \\
\text { vacuolation of } \\
\text { sporadic hepatocytes } \\
\cdot \downarrow \text { AST, ALT }\end{array}$ & $\begin{array}{l}\cdot \downarrow \text { TNF- } \alpha \\
\cdot \uparrow \text { IL-10 }\end{array}$ & $\begin{array}{l}\cdot \downarrow \mathrm{Bax} \\
\cdot \uparrow \mathrm{Bcl}-2\end{array}$ & $\begin{array}{l}\cdot \downarrow \text { matrix } \\
\text { metallo- } \\
\text { proteinase-2 }\end{array}$ & & $\cdot \downarrow \mathrm{MDA}$ & $\begin{array}{l}\cdot \downarrow \mathrm{TG} \\
\cdot \uparrow \mathrm{HDL}\end{array}$ \\
\hline [63] & $\begin{array}{l}\cdot \text { Hyper- } \\
\text { cholesterolemia } \\
\cdot 56 \text { days } \\
\cdot \text { Rabbit }\end{array}$ & $\begin{array}{l}\text { Severe } \\
\text { steatosis } \\
\text { involving }>66 \% \\
\text { of hepatocytes, } \\
\text { hepatocellular } \\
\text { ballooning, mild } \\
\text { mixed } \\
\text { inflammation } \\
\text { - Elevation of } \\
\text { liver enyzmes }\end{array}$ & $\begin{array}{l}\cdot 10 \& 20 \\
\mathrm{mg} / \mathrm{kg} / \mathrm{d} \\
\cdot \mathrm{po} \\
\cdot 56 \text { days }\end{array}$ & $\begin{array}{l}\cdot \text { Reduction of } \\
\text { steatosis and } \\
\text { inflammation } \\
\cdot \downarrow \text { AST, ALT }\end{array}$ & & & & & $\begin{array}{l}\cdot \downarrow \text { protein } \\
\text { carbonyl, } \\
\text { MDA }\end{array}$ & $\begin{array}{l}\cdot \downarrow \mathrm{HDL}, \\
\text { LDL, } \\
\text { total/HDL- } \\
\text { cholesterol }\end{array}$ \\
\hline
\end{tabular}


Table 6. Effects on liver injury caused by tumor.

\begin{tabular}{|c|c|c|c|c|c|c|c|c|c|c|}
\hline & Injur & Model & TQ & & & & ffect of TQ & & & \\
\hline $\mathbf{R}$ & $\begin{array}{l}\cdot \text { Model } \\
\cdot \text { Duration } \\
\text { of Induction } \\
\cdot \text { Species }\end{array}$ & Toxic Effect & $\begin{array}{l}\cdot \text { Dose } \\
\text { - Route of } \\
\text { Administration } \\
\text { - Duration of } \\
\text { Treatment }\end{array}$ & $\begin{array}{l}\text { Reduction of } \\
\text { Hepatic Damage }\end{array}$ & $\begin{array}{l}\text { Anti- } \\
\text { Inflammatory }\end{array}$ & $\begin{array}{l}\text { Anti-/Pro- } \\
\text { Apoptotic }\end{array}$ & Antifibrotic & $\begin{array}{l}\text { Anti- } \\
\text { Carcinogenic }\end{array}$ & $\begin{array}{l}\text { Anti- } \\
\text { Oxidative }\end{array}$ & Others \\
\hline [77] & $\begin{array}{l}\cdot \text { HCC } \\
\text { (induced by } \\
\text { injection of } \\
\text { Hep3B cells sc) } \\
\cdot \text { Tumor } \\
\text { volume } \\
\sim 150 \mathrm{~mm}^{3} \\
\text { - Mouse }\end{array}$ & $\begin{array}{l}\text { Growth of } \\
\text { tumor nodules }\end{array}$ & $\begin{array}{l}\cdot 5 \& 20 \mathrm{mg} / \mathrm{kg} / \mathrm{d} \\
\cdot \mathrm{sc} \\
\cdot 31 \text { days }\end{array}$ & $\cdot \downarrow$ tumor volume & & & & $\begin{array}{l}\cdot \uparrow \text { expression } \\
\text { of p21protein } \\
\cdot \text { inhibition of } \\
\text { NICD1 and } \\
\text { Bcl-2 }\end{array}$ & & \\
\hline [78] & $\begin{array}{l}\cdot \text { HCC } \\
\text { (induced by } \\
\text { NDEA) } \\
\text { - Preventive: } \\
16 \text { weeks; } \\
\text { Curative: } \\
11 \text { weeks } \\
\cdot \text { Rat }\end{array}$ & $\begin{array}{l}\cdot \text { Growth of } \\
\text { tumor nodules } \\
\cdot \text { Loss of } \\
\text { architecture } \\
\text { with } \\
\text { pleomorphism } \\
\text { of nuclei } \\
\text { - Elevated liver } \\
\text { tumor markers } \\
\text { and liver } \\
\text { parameters }\end{array}$ & $\begin{array}{l}\cdot 20 \mathrm{mg} / \mathrm{kg} \text { bw } \\
\text { po } \\
\text { - Preventive: } \\
3 x / \text { week for } 2 \\
\text { weeks prior } \\
\text { experiment; } \\
\text { Curative: } \\
3 x / \text { week for last } 5 \\
\text { weeks }\end{array}$ & $\begin{array}{l}\cdot \text { Reduced incidence } \\
\text { of tumor nodules } \\
\cdot \text { Normal architecture, } \\
\text { minimal } \\
\text { inflammatory and few } \\
\text { neoplastically } \\
\text { transformed } \\
\text { hepatocytes } \\
\cdot \downarrow \text { liver tumor } \\
\text { markers (AFP \& CEA) } \\
\cdot \downarrow \text { ALT, AST, LDH, } \\
\text { ALP, } \gamma \text {-GT, total } \\
\text { bilirubin }\end{array}$ & & & & $\begin{array}{l}\cdot \downarrow \text { AgNOR } \\
\cdot \text { Regulating } \\
\text { G1/s phase } \\
\text { cell cycle } \\
\text { transition }\end{array}$ & & \\
\hline [64] & $\begin{array}{l}\cdot \text { HCC } \\
\text { (induced by } \\
\text { NDEA) } \\
\cdot \text { Single dose } \\
\text { NDEA } \\
(200 \mathrm{mg} / \mathrm{kg} \mathrm{ip}) \\
\text { - Rat }\end{array}$ & $\begin{array}{l}\text { - Signs of severe } \\
\text { hepatic injury } \\
\text { (total score: } 14 \text { ) } \\
\text { - Elevation of } \\
\text { liver parameters }\end{array}$ & $\begin{array}{l}\cdot 4 \mathrm{mg} / \mathrm{kg} / \mathrm{d} \\
\cdot \text { po } \\
\cdot 7 \text { days }(5 \text { days } \\
\text { before, } 2 \text { days } \\
\text { after NDEA) }\end{array}$ & $\begin{array}{l}\cdot \text { Mild hepatic injury } \\
\text { (total score: } 6 \text { ) } \\
\cdot \downarrow \text { ALT, ALP, total } \\
\text { bilirubin }\end{array}$ & & & & & $\begin{array}{l}\cdot \downarrow \\
\text { thiobarbituric } \\
\text { acid reactive } \\
\text { substance } \\
\cdot \uparrow \text { GSH, } \\
\text { GPx, GST, } \\
\text { CAT }\end{array}$ & $\begin{array}{l}\cdot \downarrow \text { total } \\
\text { nitrate/ } \\
\text { nitrite }\end{array}$ \\
\hline
\end{tabular}


Table 7. Effects on liver injury caused by cholestasis.

\begin{tabular}{|c|c|c|c|c|c|c|c|c|c|c|}
\hline & Injur & odel & TQ & & & & ffect of TQ & & & \\
\hline $\mathbf{R}$ & $\begin{array}{l}\cdot \text { Model } \\
\text { - Duration of } \\
\text { Induction } \\
\text { - Species }\end{array}$ & Toxic Effect & $\begin{array}{l}\text { - Dose } \\
\text { · Route of } \\
\text { Administration } \\
\text { - Duration of } \\
\text { Treatment }\end{array}$ & $\begin{array}{l}\text { Reduction of } \\
\text { Hepatic } \\
\text { Damage }\end{array}$ & $\begin{array}{l}\text { Anti- } \\
\text { Inflammatory }\end{array}$ & $\begin{array}{l}\text { Anti-/Pro- } \\
\text { Apoptotic }\end{array}$ & Antifibrotic & $\begin{array}{l}\text { Anti- } \\
\text { Carcinogenic }\end{array}$ & Anti-Oxidative & Others \\
\hline$[65]$ & $\begin{array}{l}\text { - Bile duct } \\
\text { ligation } \\
\text { - Rat }\end{array}$ & $\begin{array}{l}\cdot \text { Hepatic } \\
\text { necrosis and } \\
\text { fibrosis }\end{array}$ & $\begin{array}{l}\cdot 25 \& 50 \mathrm{mg} / \mathrm{kg} \\
\cdot \text { po } \\
\cdot 2 \text { weeks (start } 3 \\
\text { days prior to } \\
\text { ligation) }\end{array}$ & $\begin{array}{l}\text { Less necrosis } \\
\text { and fibrosis }\end{array}$ & & & & & $\begin{array}{l}\cdot \downarrow \mathrm{HP} \text { and } \\
\mathrm{MDA} \\
\cdot \uparrow \mathrm{SOD} \text { and } \\
\mathrm{Gpx}\end{array}$ & \\
\hline$[66]$ & $\begin{array}{l}\text { - Bile duct } \\
\text { ligation } \\
\text { - Rat }\end{array}$ & $\begin{array}{l}\text { - Bile duct } \\
\text { proliferation } \\
\text { and fibrosis }\end{array}$ & $\begin{array}{l}\cdot 50 \mathrm{mg} / \mathrm{kg} \\
\cdot \text { po } \\
\cdot 2 \text { weeks (start } 3 \\
\text { days prior to } \\
\text { ligation) }\end{array}$ & $\begin{array}{l}\text { - Attenuation of } \\
\text { histological } \\
\text { changes }\end{array}$ & & & & & $\begin{array}{l}\cdot \downarrow \text { tissue } \\
\text { hydroxyproline } \\
\text { and MDA } \\
\cdot \uparrow \text { SOD and } \\
\text { Gpx }\end{array}$ & \\
\hline
\end{tabular}


Table 8. Effects on liver injury caused by Ischemia/Reperfusion.

\begin{tabular}{|c|c|c|c|c|c|c|c|c|c|c|}
\hline & Inju & y Model & TQ & & & & Effect of TQ & & & \\
\hline $\mathbf{R}$ & $\begin{array}{l}\text { - Model } \\
\text { - Duration of } \\
\text { Induction } \\
\text { - Species }\end{array}$ & Toxic Effect & $\begin{array}{l}\cdot \text { Dose } \\
\cdot \text { Route of } \\
\text { Administration } \\
\cdot \text { Duration of } \\
\text { Treatment }\end{array}$ & $\begin{array}{l}\text { Reduction of } \\
\text { Hepatic } \\
\text { Damage }\end{array}$ & $\begin{array}{l}\text { Anti- } \\
\text { Inflammatory }\end{array}$ & $\begin{array}{l}\text { Anti-/Pro- } \\
\text { Apoptotic }\end{array}$ & Antifibrotic & $\begin{array}{l}\text { Anti- } \\
\text { Carcinogenic }\end{array}$ & $\begin{array}{l}\text { Anti- } \\
\text { Oxidative }\end{array}$ & Others \\
\hline [67] & $\begin{array}{l}\cdot \text { Occlusion of } \\
\text { hepatic } \\
\text { pedicule } \\
\cdot 30 \text { min } \\
\text { - Rat }\end{array}$ & $\begin{array}{l}\text { Congestion of } \\
\text { central vein, } \\
\text { dilatation of } \\
\text { interstitial spaces, } \\
\text { activation of } \\
\text { Kupffer cells, } \\
\text { hepatocytes with } \\
\text { pyknotic nuclei, } \\
\text { cytoplasmic } \\
\text { degeneration, and } \\
\text { inflammatory cell } \\
\text { infiltration } \\
\text { - Elevation of liver } \\
\text { enzymes }\end{array}$ & $\begin{array}{l}\cdot 20 \mathrm{mg} / \mathrm{kg} / \mathrm{d} \\
\cdot \text { po } \\
\cdot 10 \text { days }\end{array}$ & $\begin{array}{l}\cdot \text { Moderate } \\
\text { congestion of } \\
\text { central vein, } \\
\text { slight dilation } \\
\text { of blood } \\
\text { sinusoids } \\
\cdot \downarrow \text { AST, ALT }\end{array}$ & $\downarrow \mathrm{MPO}$ & & & & $\begin{array}{l}\cdot \downarrow \mathrm{NO}, \\
\text { eNOS, iNOS, } \\
\text { NOSTRIN } \\
\cdot \uparrow \mathrm{GSH}\end{array}$ & \\
\hline [68] & $\begin{array}{l}\cdot \text { Occlusion of } \\
\text { renal artery } \\
\cdot 30 \mathrm{~min} \\
\cdot \text { Rat }\end{array}$ & Elevation of ALT & $\begin{array}{l}\cdot 10 \mathrm{mg} / \mathrm{kg} \text { bw } \\
\cdot \text { po } \\
\cdot 10 \text { days }\end{array}$ & $\cdot \downarrow$ ALT & & & & & $\begin{array}{l}\cdot \downarrow \text { MDA, } \\
\text { SSAT mRNA } \\
\text { expression } \\
\cdot \uparrow \text { GST, SOD }\end{array}$ & $\cdot \downarrow \mathrm{CYP} 3 \mathrm{~A} 1$ \\
\hline
\end{tabular}


Table 9. Effects on healthy liver.

\begin{tabular}{|c|c|c|c|c|c|c|c|c|c|c|}
\hline & Injury & Model & TQ & & & & Effect of TQ & & & \\
\hline $\mathbf{R}$ & $\begin{array}{l}\text { - Model } \\
\text { · Duration of } \\
\text { Induction } \\
\text { - Species }\end{array}$ & Toxic Effect & $\begin{array}{l}\text { - Dose } \\
\text { - Route of } \\
\text { Administration } \\
\text { - Duration of } \\
\text { Treatment }\end{array}$ & $\begin{array}{l}\text { Reduction } \\
\text { of Hepatic } \\
\text { Damage }\end{array}$ & $\begin{array}{l}\text { Anti- } \\
\text { Inflammatory }\end{array}$ & $\begin{array}{l}\text { Anti-/Pro- } \\
\text { Apoptotic }\end{array}$ & Antifibrotic & $\begin{array}{l}\text { Anti- } \\
\text { Carcinogenic }\end{array}$ & $\begin{array}{l}\text { Anti- } \\
\text { Oxidative }\end{array}$ & Others \\
\hline$[71]$ & · Mouse & & $\begin{array}{l}\cdot 1,2 \& 4 \\
\mathrm{mg} / \mathrm{kg} / \mathrm{d} \\
\cdot \mathrm{po} \\
\cdot 5 \text { days }\end{array}$ & & & & & & $\begin{array}{l}\cdot \uparrow \mathrm{GST}, \\
\text { quinone } \\
\text { reductase }\end{array}$ & \\
\hline$[70]$ & - Rabbit & & $\begin{array}{l}\cdot 10 \& 20 \\
\mathrm{mg} / \mathrm{kg} / \mathrm{d} \\
\cdot \mathrm{po} \\
\cdot 56 \text { days }\end{array}$ & & & & & & $\begin{array}{l}\cdot \uparrow \mathrm{GST}, \\
\text { Gred and } \\
\text { Gpx }\end{array}$ & $\begin{array}{l}\cdot \downarrow \text { CYP1A, } \\
\text { CYP2A4 }\end{array}$ \\
\hline
\end{tabular}

Table 10. Effects on liver injury caused by irradiation.

\begin{tabular}{|c|c|c|c|c|c|c|c|c|c|c|}
\hline & Injury & Model & TQ & & & & Effect of TQ & & & \\
\hline $\mathbf{R}$ & $\begin{array}{l}\text { - Model } \\
\text { - Duration of } \\
\text { Induction } \\
\text { - Species }\end{array}$ & Toxic Effect & $\begin{array}{l}\cdot \text { Dose } \\
\cdot \text { Route of } \\
\text { Administration } \\
\cdot \text { Duration of } \\
\text { Treatment }\end{array}$ & $\begin{array}{l}\text { Reduction } \\
\text { of Hepatic } \\
\text { Damage }\end{array}$ & $\begin{array}{l}\text { Anti- } \\
\text { Inflammatory }\end{array}$ & $\begin{array}{l}\text { Anti-/Pro- } \\
\text { Apoptotic }\end{array}$ & Antifibrotic & $\begin{array}{l}\text { Anti- } \\
\text { Carcinogenic }\end{array}$ & $\begin{array}{l}\text { Anti- } \\
\text { Oxidative }\end{array}$ & Others \\
\hline [69] & $\begin{array}{l}\cdot 5 \text { Gy gamma } \\
\cdot \text { Single dose } \\
\cdot \text { Rat }\end{array}$ & $\begin{array}{l}\cdot \text { Not } \\
\text { analyzed }\end{array}$ & $\begin{array}{l}\cdot 50 \mathrm{mg} / \mathrm{kg} / \mathrm{d} \\
\cdot \mathrm{ip} \\
\cdot 10 \text { days (start } 30 \\
\text { min prior } \\
\text { irradiation) }\end{array}$ & & & & & & $\begin{array}{l}\cdot \downarrow \text { TOS, OSI, } \\
\mathrm{LOOH} \\
\cdot \uparrow \mathrm{PON}\end{array}$ & \\
\hline
\end{tabular}




\section{Summary}

Our systematic review has summarized the effect of TQ on liver injury in experimental studies. This was done to analyze its potential suitability as a liver-protecting drug to improve IRI in transplantation as well as hepatic resection and optimize surgical outcome after hepatotoxic neoadjuvant chemotherapy. So far, no studies regarding the use of TQ in patients have been published despite the strong tradition in several countries.

For the in vivo studies, the key findings can be summarized as TQ having a strong antioxidant, anti-inflammatory, antifibrotic, anti- and proapoptotic and anticarcinogenic effect.

Despite the positive data, there are still some obstacles to be solved. First of all, in the reported studies, a wide range of doses was applied (ranging from $0.5 \mathrm{mg} / \mathrm{kg} / \mathrm{d}[49,50]$ to $100 \mathrm{mg} / \mathrm{kg} / \mathrm{d}$ [46,49]). Within this dose range, almost no side effects were reported, suggesting a wide therapeutic window. Yet, explanations of this striking broad dose range might be due to the differences in species and/or the route of administration [35,40,79]. According to toxicity studies (see Section 1.5), oral application of TQ seems to be better tolerated as signs of toxicity occurred at much higher doses than after intraperitoneal application. Overall, the $\mathrm{LD}_{50}$ values reported in several studies after both, intraperitoneal injection and oral application, were much higher than the doses of TQ reported to have desirable effects.

Furthermore, as indicated in the reported experiments, TQ modulates various signaling pathways. However, the direct mechanism of action of TQ still remains unclear.

Therefore, for better data reproducibility, but also to improve drug safety and to optimize TQ application for the discussed indications, it is essential to explore the mechanisms and doses inducing benefits and side effects.

\section{Methods}

A systematic search was performed using two databases (Medline and Cochrane Library). The search was last actualized in June 2017. Inclusion criteria were full paper publications in peer reviewed journals reporting original works or systematic reviews.

The search string was (Thymoquinone OR Nigella sativa OR Nigella sat) AND (hepar OR hepatic OR hep* OR liver) with a filter for language (English) and study settings (humans, animals), without further restrictions.

The title/abstract screening was performed by two of the authors and all publications meeting the inclusion criteria were retrieved as full text. The review was performed in accordance with the PRISMA statement (Figure 1, [48]). The main data were extracted including the publication year, study authors and countries of origin, study settings and design, dose of $\mathrm{TQ}, \mathrm{LD}_{50}$ dose and route of application.

Furthermore, the outcome of TQ administration in hepatic injury was analyzed by recording the effects of TQ in respect to histological alterations, enzyme release and the postulated mechanisms of action. To classify the main properties, subgroups were defined. The outcomes of the review were not meta-analyzable due to the lack of homogeneity of the data.

\section{Conclusions}

In parallel to the development of novel and effective treatments in modern medicine, the number of drugs with hepatotoxic effects is also increasing. For this reason, substances reducing this toxicity are urgently needed.

Due to the wide therapeutic window with strong antioxidant and anti-inflammatory effects, TQ is a promising drug candidate for IRI. Furthermore, as a hepatoprotective drug with anti-proliferative properties and little reported side effects, TQ could enhance the tolerability and effectivity of neoadjuvant therapy prior to ablative liver surgery.

To date, no attempts have been made to test the potential of TQ at the clinical level. Therefore, a sequence of preclinical and clinical assessments and studies would be adequate. 
Acknowledgments: No funds were received.

Author Contributions: Aysun Tekbas conceived the review, analyzed the data and wrote the paper; Aysun Tekbas and Jutta Huebner performed the title/abstract screening; Aysun Tekbas and Uta Dahmen designed the review; Uta Dahmen and Jutta Huebner contributed to the methods section; Uta Dahmen, Jutta Huebner and Utz Settmacher revised the review.

Conflicts of Interest: The authors declare no conflict of interest.

\section{Abbreviations}

\begin{tabular}{|c|c|}
\hline $\mathrm{AFP}$ & $\alpha$-fetoprotein \\
\hline AgNOR & Argyrophilic nucleolar organizer region \\
\hline ALP & Alkaline phosphatase \\
\hline ALT & Alanine aminotransferase \\
\hline AMPK & Adenosine monophosphate-activated protein kinase \\
\hline AST & Aspartate aminotransferase \\
\hline $\mathrm{Bcl}-2$ & B-cell lymphoma-2 \\
\hline bw & Body weight \\
\hline CAT & Catalase \\
\hline CCA & Cholangiocarcinoma \\
\hline CCI4 & Carbon tetrachloride-induced \\
\hline $\mathrm{CD}$ & Conjugated diene \\
\hline CEA & Carcinoembryonic antigen \\
\hline COX-2 & Cyclooxygenase-2 \\
\hline $\mathrm{CP}$ & Cyclophosphamide \\
\hline CsA & Cyclosporine A \\
\hline CYP & Cytochrome \\
\hline DHTQ & Dihydrothymoquinone \\
\hline EGF & Epidermal growth factor \\
\hline Gpx & Glutathione peroxidase \\
\hline Gred & Glutathione reductase \\
\hline GSH & Glutathione \\
\hline GSSG & Glutathione disulfide \\
\hline GST & Glutathione S-transferase \\
\hline GTC & Green tea catechin \\
\hline $\mathrm{HCC}$ & Hepatocellular carcinoma \\
\hline HDL & High density lipoprotein \\
\hline $\mathrm{HP}$ & Hydroxyproline \\
\hline HSC & Hepatic stellate cells \\
\hline Ig & Immunoglobulin \\
\hline IL & Interleukin \\
\hline IL-1 $\beta$ & Interleukin-1 beta \\
\hline iNOS & Inducible nitric oxide synthase \\
\hline ip & intraperitoneal \\
\hline IR & Ischemia/reperfusion \\
\hline IRI & Ischemia/reperfusion injury \\
\hline $\mathrm{LD}_{50}$ & Mean lethal dose \\
\hline $\mathrm{LDH}$ & Lactate dehydrogenase \\
\hline LDL & Low density lipoprotein \\
\hline $\mathrm{LOOH}$ & Lipid hydroperoxide \\
\hline LPO & Lipid peroxidation \\
\hline LPS & Lipopolysaccharide \\
\hline
\end{tabular}




\begin{tabular}{|c|c|}
\hline MCP-1 & Monocyte chemotactic protein-1 \\
\hline MDA & Malondialdehyde \\
\hline MIF & Migration inhibitory factor \\
\hline MnSOD & Manganese superoxide dismutase \\
\hline MPO & Myeloperoxidase \\
\hline MTX & Methotrexate \\
\hline $\mathrm{NADH}$ & Nicotinamide adenine dinucleotide \\
\hline NADPH & Nicotinamide adenine dinucleotide phosphate \\
\hline N. sativa & Nigella sativa \\
\hline NASH & Nonalcoholic steatohepatitis induced by high-fat high-cholesterol diet \\
\hline NDEA & N-Nitrosodiethylamine \\
\hline NF- $k B$ & Nuclear factor kappa-B \\
\hline NICD1 & NOTCH1 intracellular Domain \\
\hline $\mathrm{NO}$ & Nitric oxide \\
\hline NOSTRIN & Nitric oxide synthase trafficking \\
\hline Nrf2 & Nuclear respiratory factor 2 \\
\hline $\mathrm{OH}$ & Hydroxyl radical \\
\hline OSI & Oxidative stress index \\
\hline PCNA & Proliferating cell nuclear antigen \\
\hline PI3K/Akt & Phosphoinositide 3-kinase \\
\hline PON & Paraoxonase \\
\hline $\mathrm{R}$ & Reference \\
\hline ROS & Reactive oxygen species \\
\hline SAs & Sodium arsenite \\
\hline sc & subcutaneous \\
\hline SIRT1 & Hepatic sirtuin 1 \\
\hline SOD & Superoxide dismutase \\
\hline SOS & Sinusoidal obstruction syndrome \\
\hline SSAT & Spermidine/spermine N-1-acetyl-transferase \\
\hline TAS & Total antioxidant status \\
\hline TG & Triglycerides \\
\hline TGF- $\beta$ & Transforming growth factor- $\beta$ \\
\hline TIMP-1 & Tissue inhibitor of metalloproteinase- 1 \\
\hline TNF- $\alpha$ & Tumor necrosis factor- $\alpha$ \\
\hline TOS & Total oxidant status \\
\hline TQ & Thymoquinone \\
\hline VEGF & Vascular endothelial growth factor \\
\hline vLDL & Very low density lipoprotein \\
\hline$\alpha-S M A$ & $\alpha$-smooth muscle actin \\
\hline$\gamma-\mathrm{GT}$ & Gamma-glutamyl transferase \\
\hline
\end{tabular}

\section{References}

1. Arru, M.; Aldrighetti, L.; Castoldi, R.; Di Palo, S.; Orsenigo, E.; Stella, M.; Pulitano, C.; Gavazzi, F.; Ferla, G.; Di Carlo, V.; et al. Analysis of prognostic factors influencing long-term survival after hepatic resection for metastatic colorectal cancer. World J. Surg. 2008, 32, 93-103. [CrossRef] [PubMed]

2. Andreou, A.; Vauthey, J.N.; Cherqui, D.; Zimmitti, G.; Ribero, D.; Truty, M.J.; Wei, S.H.; Curley, S.A.; Laurent, A.; Poon, R.T.; et al. Improved long-term survival after major resection for hepatocellular carcinoma: A multicenter analysis based on a new definition of major hepatectomy. J. Gastrointest. Surg. 2013, 17, 66-77. [CrossRef] [PubMed]

3. Choi, D.; Lim, H.K.; Rhim, H.; Kim, Y.S.; Yoo, B.C.; Paik, S.W.; Joh, J.W.; Park, C.K. Percutaneous radiofrequency ablation for recurrent hepatocellular carcinoma after hepatectomy: Long-term results and prognostic factors. Ann. Surg. Oncol. 2007, 14, 2319-2329. [CrossRef] [PubMed] 
4. Llovet, J.M.; Fuster, J.; Bruix, J.; Barcelona-Clinic Liver Cancer, G. The Barcelona approach: Diagnosis, staging, and treatment of hepatocellular carcinoma. Liver Transpl. 2004, 10 (Suppl. 1), S115-S120. [CrossRef] [PubMed]

5. Hoff, P.M.; Ansari, R.; Batist, G.; Cox, J.; Kocha, W.; Kuperminc, M.; Maroun, J.; Walde, D.; Weaver, C.; Harrison, E.; et al. Comparison of oral capecitabine versus intravenous fluorouracil plus leucovorin as first-line treatment in 605 patients with metastatic colorectal cancer: Results of a randomized phase III study. J. Clin. Oncol. 2001, 19, 2282-2292. [CrossRef] [PubMed]

6. Adam, R.; Lucidi, V.; Bismuth, H. Hepatic colorectal metastases: Methods of improving resectability. Surg. Clin. N. Am. 2004, 84, 659-671. [CrossRef] [PubMed]

7. Belghiti, J. Surgical treatment of hepatocellular carcinoma. J. Chir. (Paris) 1999, 136, 280-283. [CrossRef] [PubMed]

8. Belghiti, J.; Kianmanesh, R. Surgical treatment of hepatocellular carcinoma. HPB (Oxford) 2005, 7, 42-49. [CrossRef] [PubMed]

9. Nordlinger, B.; Sorbye, H.; Glimelius, B.; Poston, G.J.; Schlag, P.M.; Rougier, P.; Bechstein, W.O.; Primrose, J.N.; Walpole, E.T.; Finch-Jones, M.; et al. Perioperative FOLFOX4 chemotherapy and surgery versus surgery alone for resectable liver metastases from colorectal cancer (EORTC 40983): Long-term results of a randomised, controlled, phase 3 trial. Lancet Oncol. 2013, 14, 1208-1215. [CrossRef]

10. Robinson, S.M.; Wilson, C.H.; Burt, A.D.; Manas, D.M.; White, S.A. Chemotherapy-associated liver injury in patients with colorectal liver metastases: A systematic review and meta-analysis. Ann. Surg. Oncol. 2012, 19, 4287-4299. [CrossRef] [PubMed]

11. Karoui, M.; Penna, C.; Amin-Hashem, M.; Mitry, E.; Benoist, S.; Franc, B.; Rougier, P.; Nordlinger, B. Influence of preoperative chemotherapy on the risk of major hepatectomy for colorectal liver metastases. Ann. Surg. 2006, 243, 1-7. [CrossRef] [PubMed]

12. Deleve, L.D. Sinusoidal obstruction syndrome. Gastroenterol. Hepatol. (N. Y.) 2008, 4, 101-103.

13. DeLeve, L.D.; Shulman, H.M.; McDonald, G.B. Toxic injury to hepatic sinusoids: Sinusoidal obstruction syndrome (veno-occlusive disease). Semin. Liver Dis. 2002, 22, 27-42. [CrossRef] [PubMed]

14. Takahashi, Y.; Sugimoto, K.; Inui, H.; Fukusato, T. Current pharmacological therapies for nonalcoholic fatty liver disease/nonalcoholic steatohepatitis. World J. Gastroenterol. 2015, 21, 3777-3785. [CrossRef] [PubMed]

15. Guan, L.Y.; Fu, P.Y.; Li, P.D.; Li, Z.N.; Liu, H.Y.; Xin, M.G.; Li, W. Mechanisms of hepatic ischemia-reperfusion injury and protective effects of nitric oxide. World J. Gastrointest. Surg. 2014, 6, 122-128. [CrossRef] [PubMed]

16. Zhai, Y.; Petrowsky, H.; Hong, J.C.; Busuttil, R.W.; Kupiec-Weglinski, J.W. Ischaemia-reperfusion injury in liver transplantation-From bench to bedside. Nat. Rev. Gastroenterol. Hepatol. 2013, 10, 79-89. [CrossRef] [PubMed]

17. Bent, S. Herbal medicine in the United States: Review of efficacy, safety, and regulation: Grand rounds at University of California, San Francisco Medical Center. J. Gen. Intern. Med. 2008, 23, 854-859. [CrossRef] [PubMed]

18. Cheng, F.; Li, Y.; Feng, L.; Li, S. Effects of tetrandrine on ischemia/reperfusion injury in mouse liver. Transplant. Proc. 2008, 40, 2163-2166. [CrossRef] [PubMed]

19. Liang, R.; Nickkholgh, A.; Kern, M.; Schneider, H.; Benzing, S.; Zorn, M.; Buchler, M.W.; Schemmer, P. Green tea extract ameliorates reperfusion injury to rat livers after warm ischemia in a dose-dependent manner. Mol. Nutr. Food Res. 2011, 55, 855-863. [CrossRef] [PubMed]

20. Sehirli, O.; Ozel, Y.; Dulundu, E.; Topaloglu, U.; Ercan, F.; Sener, G. Grape seed extract treatment reduces hepatic ischemia-reperfusion injury in rats. Phytother. Res. 2008, 22, 43-48. [CrossRef] [PubMed]

21. Jaeschke, H.; Woolbright, B.L. Current strategies to minimize hepatic ischemia-reperfusion injury by targeting reactive oxygen species. Transplant. Rev. (Orlando) 2012, 26, 103-114. [CrossRef] [PubMed]

22. Ferriz, J.M.; Vinsova, J. Prodrug design of phenolic drugs. Curr. Pharm. Des. 2010, 16, 2033-2052. [CrossRef] [PubMed]

23. Chang, W.C.; Hung, C.T.; Chen, Y.S.; Hsueh, C.C.; Hou, C.W.; Lay, H.L. Amelioration of carbon tetrachloride-induced hepatic injury by emulsified Antrodia extract. Iran. J. Basic Med. Sci. 2018, 21, 230-235. [PubMed]

24. Ahmad, A.; Husain, A.; Mujeeb, M.; Khan, S.A.; Najmi, A.K.; Siddique, N.A.; Damanhouri, Z.A.; Anwar, F. A review on therapeutic potential of Nigella sativa: A miracle herb. Asian Pac. J. Trop. Biomed. 2013, 3, 337-352. [CrossRef] 
25. Mollazadeh, H.; Hosseinzadeh, H. The protective effect of Nigella sativa against liver injury: A review. Iran. J. Basic Med. Sci. 2014, 17, 958-966. [PubMed]

26. Dajani, E.Z.; Shahwan, T.G.; Dajani, N.E. Overview of the Preclinical Pharmacological Properties of Nigella Sativa (Black Seeds): A Complementary Drug with Historical and Clinical Significance. J. Physiol. Pharmacol. 2016, 67, 801-817. [PubMed]

27. Pourbakhsh, H.; Taghiabadi, E.; Abnous, K.; Hariri, A.T.; Hosseini, S.M.; Hosseinzadeh, H. Effect of Nigella sativa fixed oil on ethanol toxicity in rats. Iran. J. Basic Med. Sci. 2014, 17, 1020-1031. [PubMed]

28. Sultan, M.T.; Butt, M.S.; Karim, R.; Zia-Ul-Haq, M.; Batool, R.; Ahmad, S.; Aliberti, L.; De Feo, V. Nigella sativa Fixed and Essential Oil Supplementation Modulates Hyperglycemia and Allied Complications in Streptozotocin-Induced Diabetes Mellitus. Evid. Based Complement. Alternat. Med. 2014, 2014, 826380. [CrossRef] [PubMed]

29. El-Tahir, K.E.-D.H.; Bakeet, D.M. The black seed Nigella sativa linnaeus-a mine for multi cures: A plea for urgent clinical evaluation of its volatile oil. J. Taibah Univ. Med. Sci. 2006, 1, 1-19.

30. Khare, C. Encyclopedia of Indian Medicinal Plants; Springer: Berlin/Heidelberg, Germany; New York, NY, USA, 2004.

31. Abdel-Sater, K.A. Gastroprotective effects of Nigella Sativa oil on the formation of stress gastritis in hypothyroidal rats. Int. J. Physiol. Pathophysiol. Pharmacol. 2009, 1, 143-149. [PubMed]

32. Barakat, E.M.; El Wakeel, L.M.; Hagag, R.S. Effects of Nigella sativa on outcome of hepatitis C in Egypt. World J. Gastroenterol. 2013, 19, 2529-2536. [CrossRef] [PubMed]

33. Ugur, A.R.; Dagi, H.T.; Ozturk, B.; Tekin, G.; Findik, D. Assessment of In vitro Antibacterial Activity and Cytotoxicity Effect of Nigella sativa Oil. Pharmacogn. Mag. 2016, 12 (Suppl. 4), S471-S474. [CrossRef] [PubMed]

34. Fathy, M.; Nikaido, T. In vivo modulation of iNOS pathway in hepatocellular carcinoma by Nigella sativa. Environ. Health Prev. Med. 2013, 18, 377-385. [CrossRef] [PubMed]

35. Al-Ali, A.; Alkhawajah, A.A.; Randhawa, M.A.; Shaikh, N.A. Oral and intraperitoneal LD 50 of thymoquinone, an active principle of Nigella sativa, in mice and rats. J. Ayub Med. Coll. Abbottabad 2008, 20, 25-27. [PubMed]

36. Vahdati-Mashhadian, N.; Rakhshandeh, H.; Omidi, A. An investigation on $\mathrm{LD}_{50}$ and subacute hepatic toxicity of Nigella sativa seed extracts in mice. Pharmazie 2005, 60, 544-547. [PubMed]

37. Zaoui, A.; Cherrah, Y.; Mahassini, N.; Alaoui, K.; Amarouch, H.; Hassar, M. Acute and chronic toxicity of Nigella sativa fixed oil. Phytomedicine 2002, 9, 69-74. [CrossRef] [PubMed]

38. Badary, O.A.; Al-Shabanah, O.A.; Nagi, M.N.; Al-Bekairi, A.M.; Elmazar, M.M.A. Acute and subchronic toxicity of thymoquinone in mice. Drug Dev. Res. 1998, 44, 56-61. [CrossRef]

39. El-Dakhakhny, M. Studies on the Egyptian Nigella sativa L. IV. Some pharmacological properties of the seeds' active principle in comparison to its dihydro compound and its polymer. Arzneimittelforschung 1965, 15, 1227-1229. [PubMed]

40. Mansour, M.A.; Ginawi, O.T.; El-Hadiyah, T.; El-Khatib, A.S.; Al-Shabanah, O.A.; Al-Sawaf, H.A. Effects of volatile oil constituents of Nigella sativa on carbon tetrachloride-induced hepatotoxicity in mice: Evidence for antioxidant effects of thymoquinone. Res. Commun. Mol. Pathol. Pharmacol. 2001, 110, 239-251. [PubMed]

41. Laskar, A.A.; Khan, M.A.; Rahmani, A.H.; Fatima, S.; Younus, H. Thymoquinone, an active constituent of Nigella sativa seeds, binds with bilirubin and protects mice from hyperbilirubinemia and cyclophosphamide-induced hepatotoxicity. Biochimie 2016, 127, 205-213. [CrossRef] [PubMed]

42. Houghton, P.J.; Zarka, R.; de las Heras, B.; Hoult, J.R. Fixed oil of Nigella sativa and derived thymoquinone inhibit eicosanoid generation in leukocytes and membrane lipid peroxidation. Planta Med. 1995, 61, 33-36. [CrossRef] [PubMed]

43. Mansour, M.A. Protective effects of thymoquinone and desferrioxamine against hepatotoxicity of carbon tetrachloride in mice. Life Sci. 2000, 66, 2583-2591. [CrossRef]

44. Mohany, M.; El-Feki, M.; Refaat, I.; Garraud, O.; Badr, G. Thymoquinone ameliorates the immunological and histological changes induced by exposure to imidacloprid insecticide. J. Toxicol. Sci. 2012, 37, 1-11. [CrossRef] [PubMed]

45. Nili-Ahmadabadi, A.; Tavakoli, F.; Hasanzadeh, G.; Rahimi, H.; Sabzevari, O. Protective effect of pretreatment with thymoquinone against Aflatoxin B(1) induced liver toxicity in mice. Daru 2011, 19, 282-287. [PubMed] 
46. Nagi, M.N.; Alam, K.; Badary, O.A.; Al-Shabanah, O.A.; Al-Sawaf, H.A.; Al-Bekairi, A.M. Thymoquinone protects against carbon tetrachloride hepatotoxicity in mice via an antioxidant mechanism. Biochem. Mol. Biol. Int. 1999, 47, 153-159. [PubMed]

47. Khalife, K.H.; Lupidi, G. Nonenzymatic reduction of thymoquinone in physiological conditions. Free Radic. Res. 2007, 41, 153-161. [CrossRef] [PubMed]

48. Moher, D.; Liberati, A.; Tetzlaff, J.; Altman, D.G.; Group, P. Preferred reporting items for systematic reviews and meta-analyses: The PRISMA statement. PLoS Med. 2009, 6, e1000097. [CrossRef] [PubMed]

49. Ismail, M.; Al-Naqeep, G.; Chan, K.W. Nigella sativa thymoquinone-rich fraction greatly improves plasma antioxidant capacity and expression of antioxidant genes in hypercholesterolemic rats. Free Radic. Biol. Med. 2010, 48, 664-672. [CrossRef] [PubMed]

50. Nagi, M.N.; Almakki, H.A.; Sayed-Ahmed, M.M.; Al-Bekairi, A.M. Thymoquinone supplementation reverses acetaminophen-induced oxidative stress, nitric oxide production and energy decline in mice liver. Food Chem. Toxicol. 2010, 48, 2361-2365. [CrossRef] [PubMed]

51. Abdel-Wahab, W.M. Thymoquinone attenuates toxicity and oxidative stress induced by bisphenol A in liver of male rats. Pak. J. Biol. Sci. 2014, 17, 1152-1160. [CrossRef] [PubMed]

52. Alenzi, F.Q.; El-Bolkiny Yel, S.; Salem, M.L. Protective effects of Nigella sativa oil and thymoquinone against toxicity induced by the anticancer drug cyclophosphamide. Br. J. Biomed. Sci. 2010, 67, 20-28. [CrossRef] [PubMed]

53. Al-Malki, A.L.; Sayed, A.A. Thymoquinone attenuates cisplatin-induced hepatotoxicity via nuclear factor kappa-beta. BMC Complement. Altern. Med. 2014, 14, 282. [CrossRef] [PubMed]

54. Aras, S.; Gerin, F.; Aydin, B.; Ustunsoy, S.; Sener, U.; Turan, B.C.; Armutcu, F. Effects of sodium arsenite on the some laboratory signs and therapeutic role of thymoquinone in the rats. Eur. Rev. Med. Pharmacol. Sci. 2015, 19, 658-663. [PubMed]

55. Aycan, I.O.; Tufek, A.; Tokgoz, O.; Evliyaoglu, O.; Firat, U.; Kavak, G.O.; Turgut, H.; Yuksel, M.U. Thymoquinone treatment against acetaminophen-induced hepatotoxicity in rats. Int. J. Surg. 2014, 12, 213-218. [CrossRef] [PubMed]

56. El-Sheikh, A.A.; Morsy, M.A.; Abdalla, A.M.; Hamouda, A.H.; Alhaider, I.A. Mechanisms of Thymoquinone Hepatorenal Protection in Methotrexate-Induced Toxicity in Rats. Mediat. Inflamm. 2015, 2015, 859383. [CrossRef] [PubMed]

57. Farag, M.M.; Ahmed, G.O.; Shehata, R.R.; Kazem, A.H. Thymoquinone improves the kidney and liver changes induced by chronic cyclosporine A treatment and acute renal ischaemia/reperfusion in rats. J. Pharm. Pharmacol. 2015, 67, 731-739. [CrossRef] [PubMed]

58. Hassanein, K.M.; El-Amir, Y.O. Protective effects of thymoquinone and avenanthramides on titanium dioxide nanoparticles induced toxicity in Sprague-Dawley rats. Pathol. Res. Pract. 2017, 213, 13-22. [CrossRef] [PubMed]

59. Helal, G.K. Thymoquinone supplementation ameliorates acute endotoxemia-induced liver dysfunction in rats. Pak. J. Pharm. Sci. 2010, 23, 131-137. [PubMed]

60. Mabrouk, A.; Bel Hadj Salah, I.; Chaieb, W.; Ben Cheikh, H. Protective effect of thymoquinone against lead-induced hepatic toxicity in rats. Environ. Sci. Pollut. Res. Int. 2016, 23, 12206-12215. [CrossRef] [PubMed]

61. Suddek, G.M. Protective role of thymoquinone against liver damage induced by tamoxifen in female rats. Can. J. Physiol. Pharmacol. 2014, 92, 640-644. [CrossRef] [PubMed]

62. Awad, A.S.; Abd Al Haleem, E.N.; El-Bakly, W.M.; Sherief, M.A. Thymoquinone alleviates nonalcoholic fatty liver disease in rats via suppression of oxidative stress, inflammation, apoptosis. Naunyn Schmiedebergs Arch. Pharmacol. 2016, 389, 381-391. [CrossRef] [PubMed]

63. Attia, A.; Ragheb, A.; Sylwestrowicz, T.; Shoker, A. Attenuation of high cholesterol-induced oxidative stress in rabbit liver by thymoquinone. Eur. J. Gastroenterol. Hepatol. 2010, 22, 826-834. [CrossRef] [PubMed]

64. Sayed-Ahmed, M.M.; Aleisa, A.M.; Al-Rejaie, S.S.; Al-Yahya, A.A.; Al-Shabanah, O.A.; Hafez, M.M.; Nagi, M.N. Thymoquinone attenuates diethylnitrosamine induction of hepatic carcinogenesis through antioxidant signaling. Oxid. Med. Cell. Longev. 2010, 3, 254-261. [CrossRef] [PubMed]

65. Kong, L.Y.; Li, G.P.; Yang, P.; Xi, Z. Protective effect of thymoquinone on cholestatic rats with liver injury. Genet. Mol. Res. 2015, 14, 12247-12253. [CrossRef] [PubMed] 
66. Oguz, S.; Kanter, M.; Erboga, M.; Erenoglu, C. Protective effects of thymoquinone against cholestatic oxidative stress and hepatic damage after biliary obstruction in rats. J. Mol. Histol. 2012, 43, 151-159. [CrossRef] [PubMed]

67. Abd-Elbaset, M.; Arafa, E.A.; El Sherbiny, G.A.; Abdel-Bakky, M.S.; Elgendy, A.N. Thymoquinone mitigate ischemia-reperfusion-induced liver injury in rats: A pivotal role of nitric oxide signaling pathway. Naunyn Schmiedebergs Arch. Pharmacol. 2017, 390, 69-76. [CrossRef] [PubMed]

68. Awad, A.S.; Kamel, R.; Sherief, M.A. Effect of thymoquinone on hepatorenal dysfunction and alteration of CYP3A1 and spermidine/spermine N-1-acetyl-transferase gene expression induced by renal ischaemiareperfusion in rats. J. Pharm. Pharmacol. 2011, 63, 1037-1042. [CrossRef] [PubMed]

69. Cikman, O.; Taysi, S.; Gulsen, M.T.; Demir, E.; Akan, M.; Diril, H.; Kiraz, H.A.; Karaayvaz, M.; Tarakcioglu, M. The radio-protective effects of caffeic acid phenethyl ester and thymoquinone in rats exposed to total head irradiation. Wien. Klin. Wochenschr. 2015, 127, 103-108. [CrossRef] [PubMed]

70. Elbarbry, F.; Ragheb, A.; Marfleet, T.; Shoker, A. Modulation of hepatic drug metabolizing enzymes by dietary doses of thymoquinone in female New Zealand White rabbits. Phytother. Res. 2012, 26, 1726-1730. [CrossRef] [PubMed]

71. Nagi, M.N.; Almakki, H.A. Thymoquinone supplementation induces quinone reductase and glutathione transferase in mice liver: Possible role in protection against chemical carcinogenesis and toxicity. Phytother. Res. 2009, 23, 1295-1298. [CrossRef] [PubMed]

72. Galaly, S.R.; Ahmed, O.M.; Mahmoud, A.M. Thymoquinone and curcumin prevent gentamicin-induced liver injury by attenuating oxidative stress, inflammation and apoptosis. J. Physiol. Pharmacol. 2014, 65, 823-832. [PubMed]

73. Bai, T.; Yang, Y.; Wu, Y.L.; Jiang, S.; Lee, J.J.; Lian, L.H.; Nan, J.X. Thymoquinone alleviates thioacetamideinduced hepatic fibrosis and inflammation by activating LKB1-AMPK signaling pathway in mice. Int. Immunopharmacol. 2014, 19, 351-357. [CrossRef] [PubMed]

74. Ghazwani, M.; Zhang, Y.; Gao, X.; Fan, J.; Li, J.; Li, S. Anti-fibrotic effect of thymoquinone on hepatic stellate cells. Phytomedicine 2014, 21, 254-260. [CrossRef] [PubMed]

75. Yang, Y.; Bai, T.; Yao, Y.L.; Zhang, D.Q.; Wu, Y.L.; Lian, L.H.; Nan, J.X. Upregulation of SIRT1-AMPK by thymoquinone in hepatic stellate cells ameliorates liver injury. Toxicol. Lett. 2016, 262, 80-91. [CrossRef] [PubMed]

76. Abdelghany, A.H.; BaSalamah, M.A.; Idris, S.; Ahmad, J.; Refaat, B. The fibrolytic potentials of vitamin D and thymoquinone remedial therapies: Insights from liver fibrosis established by $\mathrm{CCl}_{4}$ in rats. J. Transl. Med. 2016, 14, 281. [CrossRef] [PubMed]

77. Ke, X.; Zhao, Y.; Lu, X.; Wang, Z.; Liu, Y.; Ren, M.; Lu, G.; Zhang, D.; Sun, Z.; Xu, Z.; et al. TQ inhibits hepatocellular carcinoma growth in vitro and in vivo via repression of Notch signaling. Oncotarget 2015, 6, 32610-32621. [CrossRef] [PubMed]

78. Raghunandhakumar, S.; Paramasivam, A.; Senthilraja, S.; Naveenkumar, C.; Asokkumar, S.; Binuclara, J.; Jagan, S.; Anandakumar, P.; Devaki, T. Thymoquinone inhibits cell proliferation through regulation of G1/S phase cell cycle transition in N-nitrosodiethylamine-induced experimental rat hepatocellular carcinoma. Toxicol. Lett. 2013, 223, 60-72. [CrossRef] [PubMed]

79. Wang, Y.; Ning, Z.H.; Tai, H.W.; Long, S.; Qin, W.C.; Su, L.M.; Zhao, Y.H. Relationship between lethal toxicity in oral administration and injection to mice: Effect of exposure routes. Regul. Toxicol. Pharmacol. 2015, 71, 205-212. [CrossRef] [PubMed]

(C) 2018 by the authors. Licensee MDPI, Basel, Switzerland. This article is an open access article distributed under the terms and conditions of the Creative Commons Attribution (CC BY) license (http:/ / creativecommons.org/licenses/by/4.0/). 